\begin{tabular}{|l|l|}
\hline Title: & $\begin{array}{l}\text { Analysis of shear-transfer actions on one-way RC members based on measured } \\
\text { cracking pattern and failure kinematics }\end{array}$ \\
\hline Authors: & Campana S., Fernández Ruiz M., Anastasi A., Muttoni A. \\
\hline Published in: & $\begin{array}{l}\text { Magazine of Concrete Research } \\
\text { http://www.icevirtuallibrary.com/content/serial/macr }\end{array}$ \\
\hline DOI & $10.1680 /$ macr.12.00142 \\
\hline Pages: & $19 \mathrm{p}$. \\
\hline Country: & $\mathrm{UK}$ \\
\hline Year of publication: & 2013 \\
\hline Type of publication: & Peer reviewed journal article \\
\hline
\end{tabular}

Please quote as:

Campana S., Fernández Ruiz M., Anastasi A., Muttoni A., Analysis of shear-transfer actions on one-way RC members based on measured cracking pattern and failure kinematics, Magazine of Concrete Research, UK, 2013, 19 p.. 


\section{Analysis of shear-transfer actions on one-way RC members based on measured cracking pattern and failure kinematics}

\section{Stefano Campana}

Research assistant, IBETON-ENAC, Ecole Polytechnique Fédérale de Lausanne, Lausanne, Switzerland

\section{Miguel Fernández Ruiz}

Lecturer, IBETON-ENAC, Ecole Polytechnique Fédérale de Lausanne, Lausanne, Switzerland

\section{Andrea Anastasi}

Research assistant, IBETON-ENAC, Ecole Polytechnique Fédérale de Lausanne, Lausanne, Switzerland

Aurelio Muttoni

Professor, IBETON-ENAC, Ecole Polytechnique Fédérale de Lausanne, Lausanne, Switzerland

Shear in one-way reinforced concrete (RC) members is transferred in cracked concrete members by a number of actions such as aggregate interlock, residual tensile stresses, dowelling action, inclination of compression chord and transverse reinforcement (if available). The amount of shear transferred by each action is significantly influenced by the cracking pattern (shape of shear cracks) and by the kinematics at failure (opening and sliding of the cracks). In this paper, the activation of the various shear-transfer actions is investigated for one-way RC members. This is done by using a set of detailed measurements on the cracking pattern and actual kinematics at failure recorded on a number of specimens (beams) with a very low amount of transverse reinforcement. The amount of shear transferred by each action is estimated on the basis of available physical models and compared for the various specimens. The results show rather good predictions in terms of strength by following this approach. Consistent explanations of the shear transferred by each action are provided.

\section{Notation}

$A_{\mathrm{c}}$

$\bar{A}_{w}$

$\bar{A}_{\Delta}$

$a$

$\bar{a}_{w}$

$\bar{a}_{\Delta}$

b

$c$

$c_{1}, c_{2}$

d

$d_{\mathrm{b}}$

$d_{\text {bw }}$

$d_{\mathrm{g}}$

$E_{\mathrm{s}}$

$E_{\text {shw }}$

$E_{\mathrm{sw}}$

F

$\boldsymbol{F}_{\mathrm{tw}}$ concrete surface

sum of projections of contact surfaces $\left(\bar{a}_{w}\right)$ between aggregates normal to crack

sum of projections of contact surfaces $\left(\bar{a}_{\Delta}\right)$ between aggregates tangential to crack

shear span (distance between axis of load and support)

projection of contact surface between aggregates normal to crack

projection of contact surface between aggregates tangential to crack

width of member

concrete cover thickness of flexural reinforcement

fracture energy constants

effective depth of member

diameter of reinforcing bar

diameter of stirrup

maximum aggregate size

modulus of elasticity of steel (flexural reinforcement) modulus of hardening of steel (web reinforcement) modulus of elasticity of steel (web reinforcement)

force

force leading to tension rupture of an embedded (bonded) stirrup
$\boldsymbol{F}_{\mathrm{w}} \quad$ tension force in an embedded (bonded) stirrup

$\boldsymbol{F}_{\mathrm{yw}} \quad$ force leading to yielding of an embedded (bonded) stirrup

$f_{\mathrm{c}} \quad$ compressive strength of concrete (cylinder)

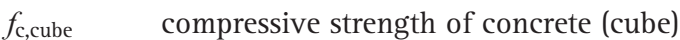

$f_{\mathrm{ct}} \quad$ tensile strength of concrete (measured in cylinder)

$f_{\mathrm{ct}, 28} \quad$ tensile strength of concrete at 28 days (cylinder)

$f_{\mathrm{tw}}$ tensile strength of steel (web reinforcement) yield strength of steel (flexural reinforcement) yield strength of steel (web reinforcement) fracture energy height of member span length of tested member distance from critical shear crack to edge of support plate

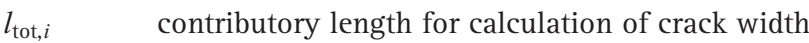

$\boldsymbol{N}_{\text {agg }} \quad$ horizontal component of aggregate interlock action

$\boldsymbol{N}_{\mathrm{ch}} \quad$ horizontal component of inclined compression chord

$N_{i} \quad$ horizontal component of shear-transfer action $i$

$\boldsymbol{N}_{\text {res }} \quad$ horizontal component of the residual tensile strength of concrete tension force in flexural reinforcement distance between crack $i-1$ and crack $i$ 
opening of a crack measured along the horizontal direction

$V \quad$ shear force

$\boldsymbol{V}_{\text {agg }} \quad$ shear force carried by aggregate interlock action

$\boldsymbol{V}_{\mathrm{ch}} \quad$ shear force carried by inclined compression chord

$\boldsymbol{V}_{\text {dow }} \quad$ shear force carried by dowel action

$\boldsymbol{V}_{i} \quad$ shear force carried by the shear-transfer action $i$

$V_{\max } \quad$ shear strength of member

$\boldsymbol{V}_{\max , \mathrm{a}} \quad$ shear strength of member on the side without transverse reinforcement

$\boldsymbol{V}_{\max , \mathrm{b}} \quad$ shear strength of member on the side with transverse reinforcement

$V_{\mathrm{p}} \quad$ shear force acting at last measurement step

$\boldsymbol{V}_{\text {res }} \quad$ shear force carried by residual tensile strength of concrete

$V_{\text {sw }} \quad$ shear force carried by transverse reinforcement

$\boldsymbol{V}_{\mathrm{sw} 1}-\boldsymbol{V}_{\mathrm{sw} 9}$ shear force carried by stirrups 1 to 9

$V_{\text {tot }} \quad$ total computed shear force

$v \quad$ opening of crack measured along the vertical direction relative vertical displacement (with respect to concrete) of flexural reinforcement at location of the critical crack vertical crack opening of an inclined crack crossing a stirrup vertical crack opening leading to tension rupture of an embedded (bonded) stirrup vertical crack opening leading to first yielding of an embedded (bonded) stirrup opening of the crack measured along the axis $y^{\prime}$ normal to the crack maximum crack width allowing tensile stresses transfer in concrete

$w_{i} \quad$ opening of crack $i$

$w_{0} \quad$ fraction of the total crack opening $(w)$ developing prior to crack sliding coordinate in horizontal axis coordinate in axis tangential to the crack coordinate in vertical axis coordinate in vertical axis normal to the crack inclination of crack surface inclination of compression chord angle (with respect to the crack plane) of the displacement that follows initial opening of the crack $\left(w_{0}\right)$ sliding of crack measured along the axis $x^{\prime}$ tangential to the crack

displacement (opening and sliding) after opening of the crack $\left(w_{0}\right)$ relative steel-concrete slip relative steel-concrete slip at yielding of the reinforcement measured deflection of member at mid-span strain of concrete $\varepsilon_{\mathrm{ct}} \quad$ strain corresponding to the tensile strength of

\section{concrete}

$\varepsilon_{\mathrm{s}} \quad$ strain of steel

$\varepsilon_{\mathrm{s}, i} \quad$ strain of steel at location of crack $i$

$\varepsilon_{\text {sy }} \quad$ yield strain of steel

$\mu \quad$ coefficient of friction

$\rho \quad$ flexural reinforcement ratio

$\rho_{\mathrm{w}} \quad$ transverse reinforcement ratio

$\sigma_{\text {agg }} \quad$ aggregate interlock normal stress

$\sigma_{\mathrm{c}} \quad$ concrete stress

$\sigma$ pu compressive plastic strength of cement matrix

$\sigma$ res residual tensile strength of concrete

$\sigma_{\mathrm{s}} \quad$ stress of steel

$\sigma_{\mathrm{s}, i} \quad$ stress of steel at location of crack $i$

$\sigma_{\text {sw }} \quad$ stress of stirrup

$\bar{\sigma} \quad$ resultant of main compressive aggregate interlock stress

$\tau$ agg aggregate interlock shear stress

$\tau_{\mathrm{b}} \quad$ bond stress

$\tau_{\text {bo }} \quad$ bond stress prior to yielding of reinforcement

$\tau_{\mathrm{b} 1} \quad$ bond stress after yielding of reinforcement

\section{Introduction}

Shear-transfer actions in one-way reinforced concrete members

After concrete cracks, a number of actions can transfer shear forces in the concrete member. Kani $(1964,1966)$ investigated this phenomenon by considering the strength of the concrete teeth between two flexural cracks. In a general manner (Muttoni and Fernández Ruiz, 2008), shear can be transferred by the concrete teeth through actions such as cantilever action (Figure 1(a)), aggregate interlock action (Figure 1(b)) or dowel action of the flexural reinforcement (Figure 1(c)). These actions cause a state of stress in the member such that flexural cracks propagate into shear cracks (Figure 1(d)), thus reducing their load-carrying capacity or completely disabling some of them (with the residual strength of concrete in tension after cracking potentially playing a role in this situation). However, even after the development of an inclined shear crack, shear can still be transferred and this accounts for the inclination of the compression chord (whose strength depends on the aggregate interlock capacity (Muttoni and Fernández Ruiz, 2008)), which allows the development of arching action (direct strutting of loads (see Figure 1(e)).

When the strength provided by these actions is insufficient for the acting loads, shear reinforcement can be provided to increase the strength and deformation capacity of the member. Shear reinforcement helps to limit crack widths (thus increasing the efficiency of the previous shear-carrying actions) and may be used to carry shear forces directly in combination with aggregate interlocking and/or arching actions (see Figure 1(f)).

Shear-carrying actions have been investigated by a number of authors. Fenwick and Paulay (1968) were among the first to 

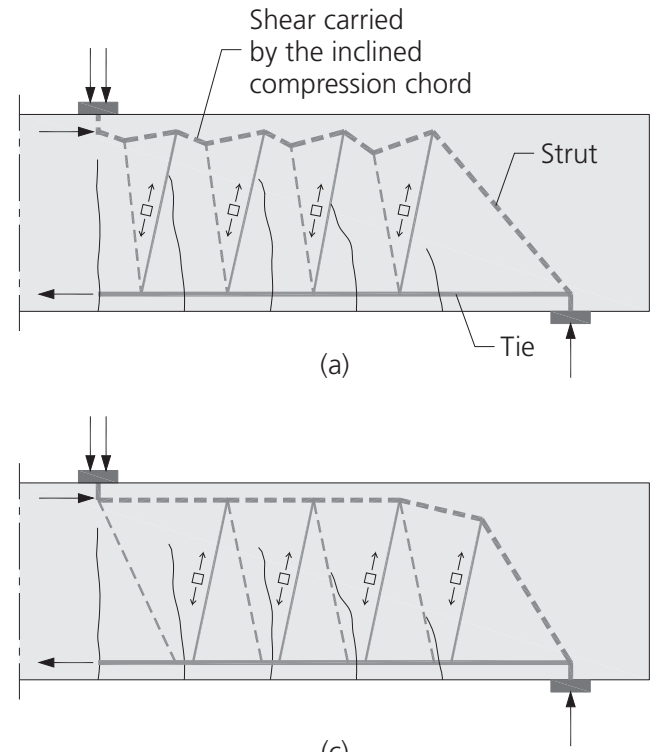

(c)

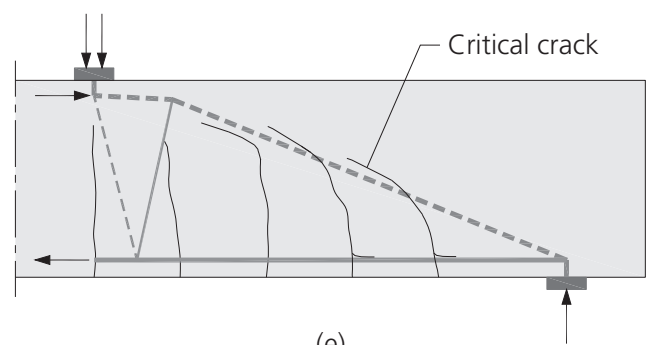

(e)

Figure 1. Beam shear-transfer actions in cracked RC members. (a) Cantilever action. (b) Aggregate interlock action. (c) Dowel action. (d) Propagation of flexural crack due to tensile stresses in concrete. (e) Final cracking pattern and critical shear crack.

(f) Behaviour of RC members with transverse reinforcements
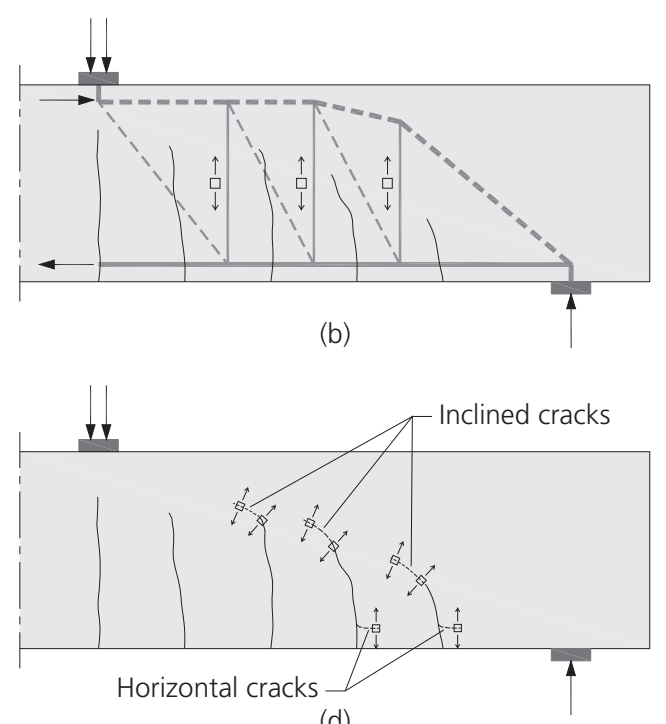

(d)

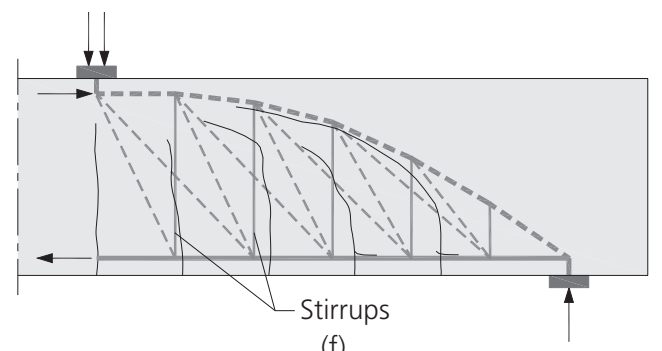

(f) investigate the role of the cracking pattern on shear-transfer actions by testing a number of pre-cracked specimens under various configurations. Other researchers have focused on developing physical models to assess the amount of shear force that can be transferred (locally or by a structural member) under a specific shear-transfer action (or a combination of them) assuming given kinematics at failure. Some significant works in this field have been performed on the aggregate interlock action (Dei Poli et al., 1987; Paulay and Loeber, 1974; Sagaseta and Vollum, 2011; Taylor, 1970; Ulaga, 2003; Walraven, 1980; Zararis, 1997), the dowelling action (Chana, 1987; Dei Poli et al., 1992, 1993; Jelic et al., 1999; Krefeld and Thurston Charles, 1966a, 1966b; Paulay et al., 1974; Taylor, 1969; Zararis, 2003), the influence of the residual tensile strength of concrete (Bažant and Kazemi, 1991; Bažant and Yu, 2005a, 2005b, 2009; Hillerborg, 1983; Hordijk, 1992; Kotsovos, 1983, 1986) and the contribution of the compression zone to carry shear forces (Tureyen and Frosch, 2003).

In this paper, the amount of shear transferred by the various actions is estimated for three specimens tested by the authors. All beams were $400 \mathrm{~mm}$ high and were provided with a very small amount of transverse reinforcement $\left(\rho_{\mathrm{w}}=0.063 \%\right)$ - lower than the minimum amount required by design codes (ACI, 2008; CEN, 2004; fib, 2011). The tests were performed to provide very accurate measurements on the crack patterns and kinematics at failure in order to allow application of a set of physical models available for each shear-transfer action to the measured kinematics in order to calculate the shear transferred by each action. The low amount of transverse reinforcement was provided in order to control crack development - members without transverse reinforcement can lead to sudden crack propagation (Fernández Ruiz et al., 2009), thus not allowing accurate readings to be taken. In addition, members with very low transverse reinforcement (lower than the minimal) are among the most interesting from a phenomenological point of view as they usually show larger scatter in terms of strength, shape of the critical shear crack and deformation capacity. This is justified because the various shear-transfer actions can contribute in a different manner and with varying intensity depending on the actual crack shapes 
and kinematics. This was observed in the tested specimens and will be explained and justified in this paper on the basis of the performed measurements.

\section{Experimental programme}

The investigated specimens had a rectangular cross-section of $300 \times 400 \mathrm{~mm}$ (see Figure 2(a)). Specimens SC12 and SC13 were cast in normal-strength concrete (NSC) and the other two specimens (SC16 and SC17) were cast in self-compacting concrete (SCC). Maximum aggregate size $d_{\mathrm{g}}$ was $16 \mathrm{~mm}$ for both types of concrete and the granulometry was roughly similar (see Table 1). Cylindrical concrete compressive strength at the day of the test $\left(f_{\mathrm{c}}\right)$ was $41 \cdot 2-43 \cdot 1 \mathrm{MPa}$ for NSC specimens and $55 \cdot 7-$ $57.2 \mathrm{MPa}$ for SCC specimens. The concrete tensile strength $f_{\mathrm{ct}, 28}$, measured at 28 days by direct tension tests on cylinders of diameter $160 \mathrm{~mm}$, was $2.93 \mathrm{MPa}$ for NSC specimens and 3.17 MPa for SCC specimens.

The nominal flexural reinforcement ratio for specimens SC12 and SC16 was $\rho=1.53 \%$ (three bars of diameter $26 \mathrm{~mm}$ ) and $\rho=1.09 \%$ (three bars of diameter $22 \mathrm{~mm}$ ) for specimens SC13 and SC17. The longitudinal reinforcement was hot rolled with a well-defined yield plateau $\left(f_{\mathrm{y}}=580 \mathrm{MPa}\right.$ for both diameters of 22 and $26 \mathrm{~mm}$ ) (see Figures 2(b) and 2(c)). The nominal concrete
Mass: $\mathrm{kg}$

Normal-strength Self-compacting concrete concrete

\begin{tabular}{lll}
\hline Water & 123 & 196 \\
Cement & 326 & 450 \\
Sand $(0-4 \mathrm{~mm})$ & 894 & 877 \\
Fine gravel $(4-8 \mathrm{~mm})$ & 430 & 351 \\
Coarse gravel $(8-16 \mathrm{~mm})$ & 627 & 526
\end{tabular}

Table 1. Composition of concrete (per cubic metre)

cover was $c=40 \mathrm{~mm}$, thus the nominal effective depth $d$ was $347 \mathrm{~mm}$ for specimens SC12 and SC16 and $349 \mathrm{~mm}$ for specimens SC13 and SC17.

A sketch of the test setup is shown in Figure 2(a). The simply supported beams were loaded (under controlled displacements) in three-point bending, with a span length $L=2440 \mathrm{~mm}$. The concentrated load was applied at mid-span. The nominal shear span-to-effective depth ratio $a / d$ (where $a=L / 2$ refers to the distance between the axis of the load and of the support) was

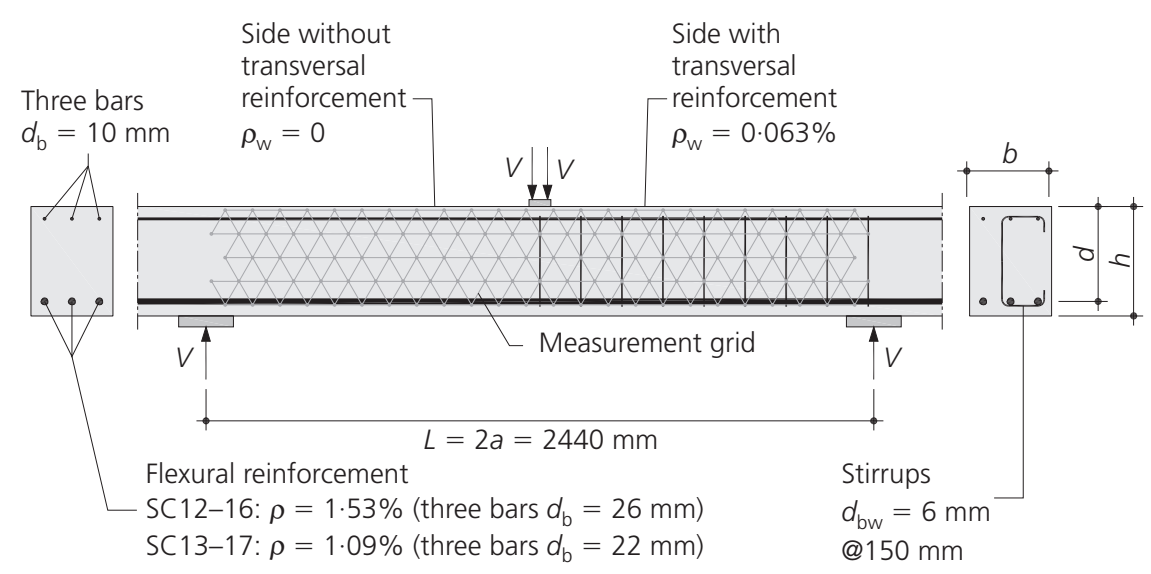

(a)

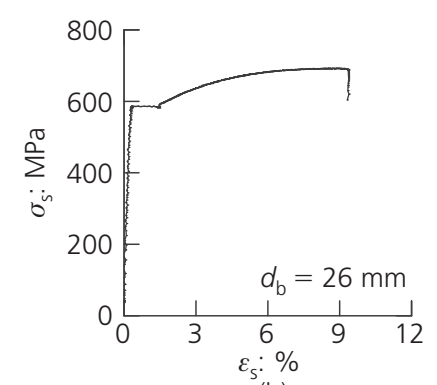

(b)

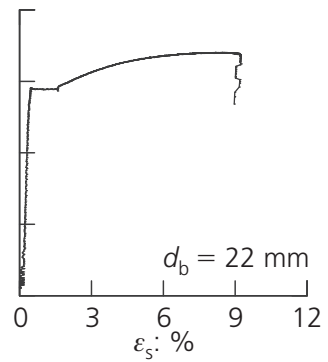

(c)

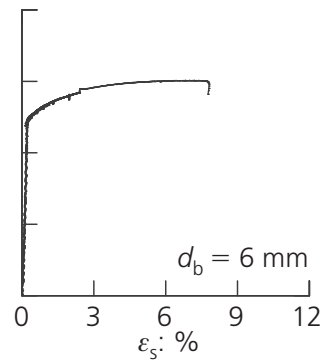

(d)

Figure 2. (a) Test setup. Measured stress-strain relationship for reinforcement: (b) flexural bars (diameter $26 \mathrm{~mm}$ ); (c) flexural bars (diameter $22 \mathrm{~mm}$ ); (d) stirrups (diameter $6 \mathrm{~mm}$ ). 
equal to 3.5. The loading plate under the hydraulic jack had dimensions of $300 \times 80 \times 25 \mathrm{~mm}$ and was fixed horizontally. Two bearing plates (dimensions $300 \times 200 \times 40 \mathrm{~mm}$ ) were placed over the support rollers and allowed free horizontal movements as well as rotations.

Two failures were obtained for each specimen, giving a total of eight tests. The first failure (called failure 'a') was obtained on the side of the specimen without transverse reinforcement. The specimens were then strengthened by the addition of external steel plates and threaded bars and reloaded again. This led to a second failure (failure ' $b$ ') developing in the side with transverse reinforcement $\left(\rho_{\mathrm{w}}=0.063 \%\right.$ ). This low value of $\rho_{\mathrm{w}}$ was obtained by using $6 \mathrm{~mm} \mathrm{C}$-shaped pins placed at $150 \mathrm{~mm}$ (placing of the horizontal branches was alternate for two consecutive stirrups, leading to a symmetrical geometry for the specimen; see Figure 2(a)). The steel used for the stirrups was cold worked with a yield strength $f_{\mathrm{yw}}$ of $497 \mathrm{MPa}(0 \cdot 2 \%$ residual strain; see Figure 2(d)).

All details concerning the properties of specimens (material properties and tests results) are summarised in Table 2. The measured load-deflection curves for the eight tests are presented in Figures 3(a)-3(d). The shapes of the critical shear cracks are compared for failures in the side without transverse reinforcement in Figure 3(e) and with transverse reinforcement in Figure 3(f).

\section{Discussion of test results}

The results for the tests without transverse reinforcement show higher normalised shear strengths for the two members cast in NSC than those cast in SCC for the same amount of flexural reinforcement. This tendency is, however, not observed for members with transverse reinforcement, where the shear strength depends most on the amount of flexural reinforcement (with larger shear strengths for larger amounts of flexural reinforcement) and shows no significant correlation to the type of concrete used.

The deformation capacity consistently increased for members with stirrups as a function of the increase in shear strength of the member (increasing capacities of deformation for increasing shear strengths). A change in the load-deflection slope (softer response and thus larger deformation capacities) occurred prior to failure. This happened at load levels higher than those leading to shear failures for the corresponding tests without shear reinforcement, and was particularly significant for test SC16b. This behaviour is explained by the development and significant opening of an inclined shear crack (eventually leading to the shear failure) increasing the rotations (and deflections) of the member. More details on shear crack kinematics (opening) and its implications on the behaviour of the member will be discussed later in the paper.

For members without transverse reinforcement, the location and shape of the critical shear cracks were broadly similar (Figure 3(e)). On the contrary, the critical shear cracks on the side with transverse reinforcement showed two possibilities (Figure 3(f)) a critical shear crack located at the level of the flexural reinforcement close to the support edge (tests $\mathrm{SC} 13 \mathrm{~b}$ and $\mathrm{SC} 16 \mathrm{~b}$ ) or a critical shear crack shifted further from the support (tests SC12b and $\mathrm{SC} 17 \mathrm{~b}$ ) and with a region (close to the flexural reinforcement) with a steeper slope. The location of the cracks seems to be influenced by that of the stirrups, with the top and bottom ends of the steepest part of each shear crack located in between two stirrups. This thus leads to the two observed shapes, where the bottom part of the critical shear crack corresponds respectively to the second or third stirrup from the edge of the support. However, no clear trend was observed between the type of concrete or amount of reinforcement and the shape and location of the shear cracks (see Figure 3(f)).

The shape, location and kinematics of the shear cracks imply that, for members with low transverse reinforcement, the contribution provided by each shear-transfer action may potentially be rather different. For these tests, the complete crack patterns at the last measurement step before failure and at failure are shown in Figure 4. In the following sections, tests $\mathrm{SC} 12 \mathrm{~b}, \mathrm{SC} 13 \mathrm{~b}$ and $\mathrm{SC16b}$ (failures in the side with transverse reinforcement) will be investigated based on measured crack kinematics with the aim of

\begin{tabular}{|c|c|c|c|c|c|c|c|c|c|c|c|c|c|}
\hline Specimen & Concrete & $\begin{array}{c}b: \\
m m\end{array}$ & $\begin{array}{c}h: \\
\mathrm{mm}\end{array}$ & $\begin{array}{c}d: \\
\mathrm{mm}\end{array}$ & $\begin{array}{l}\rho: \\
\%\end{array}$ & $\begin{array}{l}d_{g}: \\
\mathrm{mm}\end{array}$ & $\begin{array}{l}f_{\mathrm{ct}, 28}: \\
\mathrm{MPa}\end{array}$ & $\begin{array}{c}f_{\mathrm{y}}: \\
\mathrm{MPa}\end{array}$ & Test & $\begin{array}{c}\rho_{\mathrm{w}}: \\
\%\end{array}$ & $\begin{array}{c}f_{\mathrm{c}}: \\
\mathrm{MPa}\end{array}$ & $\begin{array}{l}f_{y w}: \\
M P a\end{array}$ & $\underset{k N}{V_{\max }:}$ \\
\hline SC12 & NSC & 302 & 405 & 354 & $1 \cdot 51$ & 16 & $2 \cdot 93$ & 580 & $\begin{array}{l}a \\
b\end{array}$ & $\begin{array}{l}0 \\
0.063\end{array}$ & $\begin{array}{l}41 \cdot 2 \\
41 \cdot 5\end{array}$ & - & $\begin{array}{l}148 \\
176\end{array}$ \\
\hline SC13 & NSC & 303 & 403 & 354 & 1.07 & 16 & 2.93 & 580 & $\begin{array}{l}a \\
b\end{array}$ & $\begin{array}{l}0 \\
0.063\end{array}$ & $\begin{array}{l}43 \cdot 0 \\
43 \cdot 1\end{array}$ & - & $\begin{array}{l}137 \\
150\end{array}$ \\
\hline SC16 & SCC & 302 & 402 & 346 & $1 \cdot 53$ & 16 & $3 \cdot 17$ & 580 & $\begin{array}{l}a \\
b\end{array}$ & $\begin{array}{l}0 \\
0.063\end{array}$ & $\begin{array}{l}55 \cdot 7 \\
56 \cdot 0\end{array}$ & - & $\begin{array}{l}115 \\
199\end{array}$ \\
\hline SC17 & SCC & 304 & 404 & 350 & 1.09 & 16 & $3 \cdot 17$ & 580 & $\begin{array}{l}a \\
b\end{array}$ & $\begin{array}{l}0 \\
0.063\end{array}$ & $\begin{array}{l}56 \cdot 7 \\
57 \cdot 2\end{array}$ & - & $\begin{array}{l}127 \\
153\end{array}$ \\
\hline
\end{tabular}

Table 2. Summary of geometry, materials properties and

strength of tested specimens 


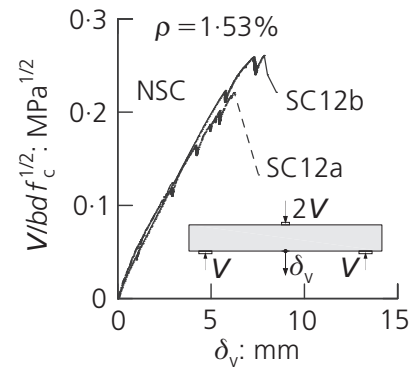

(a)

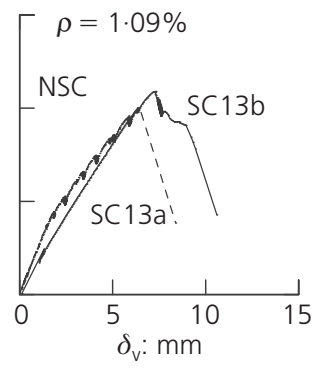

(b)

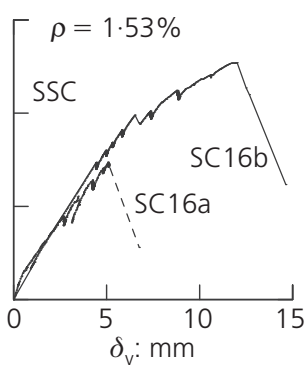

(c)

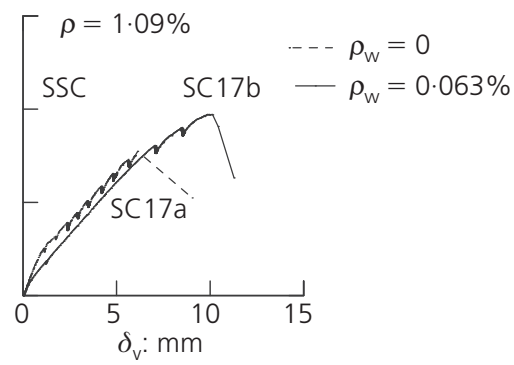

(d)

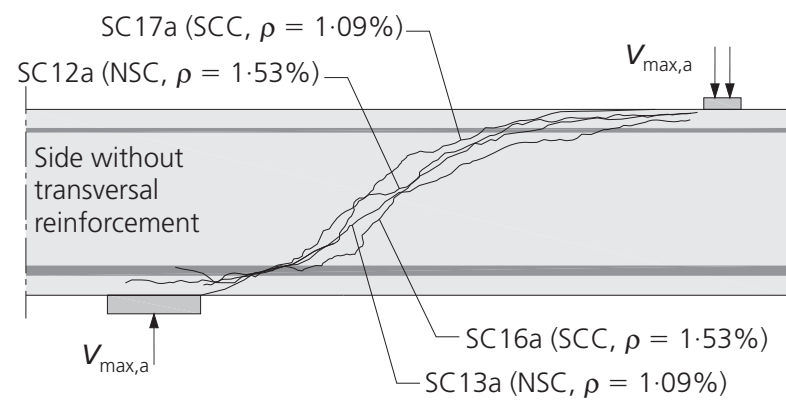

(e)

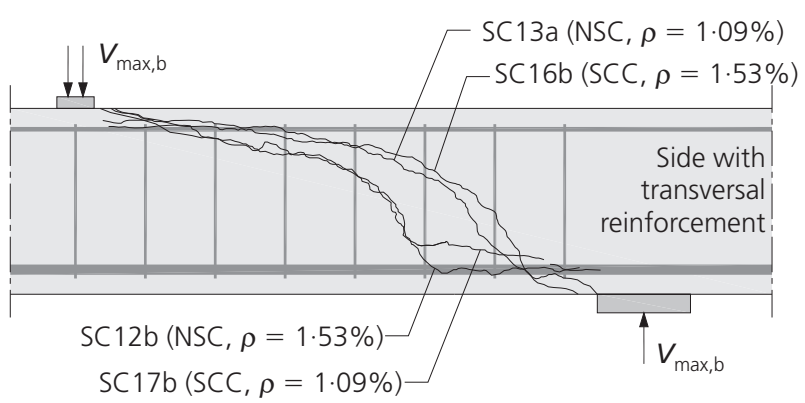

(f)

Figure 3. Load-deformation curves obtained on tests without (failure ' $a$ ') and with (failure ' $b$ ') transversal reinforcements for specimens: (a) SC12; (b) SC13; (c) SC16; (d) SC17. Observed critical shear cracks on sides without transversal reinforcements (e) and with transversal reinforcements ( $f$ )

calculating the shear carried by each shear-transfer action. Test $\mathrm{SC} 17 \mathrm{~b}$ is not considered because two inclined cracks developed at failure in the measurement area (see Figures 4(d) and 2(h)), thus preventing determination of the actual kinematics (opening and sliding) of each crack.

\section{Measurement of crack kinematics}

Discrete measurements were performed on one side of the specimen to track the development of cracking during testing. These measurements were manually performed at different load steps with a Demec device (high-precision distance measurement device) on metallic measuring targets glued to the concrete surface. These targets were arranged as a grid of equilateral triangular elements with a nominal side length of $100 \mathrm{~mm}$ (see Figure 2(a)). The measurements were performed at selected load levels. The last measurement step (see Figures 4(a)-4(c)) was performed at a load level $\left(\boldsymbol{V}_{\mathrm{p}}\right)$ corresponding to $99 \%$ of the maximum applied shear load $\left(\boldsymbol{V}_{\max , \mathrm{b}}\right)$ for test $\mathrm{SC} 12 \mathrm{~b}, 100 \%$ of $\boldsymbol{V}_{\text {max,b }}$ for test $\mathrm{SC} 13 \mathrm{~b}$ and $88 \%$ of $\boldsymbol{V}_{\text {max,b }}$ for test SC16b. These load levels correspond to the maximum load of the measurement step (the measurements were only started after the load stabilised, at a slightly lower level than the maximum load of the measurement step). As shown in Figures 4(a)-4(c), the critical cracks defining the rigid bodies for these tests were sufficiently developed at the last load level where Demec measurements were performed.
Accurate Demec measurements were essential for the analysis presented in this paper, since all the results were obtained from these measurements. In order to improve accuracy, ten readings of each measurement were performed (they were automatically acquired by the measurement device within $1 \mathrm{~s}$ ). The standard deviation of the readings was checked and the measurement was validated if its standard deviation was lower than $0.002 \mathrm{~mm}$ (for the measurement length of $100 \mathrm{~mm}$ ). The readings were later corrected to minimise measuring errors. This was done by using a finite-element analysis of a truss model reproducing the measuring targets where the measured relative displacements were introduced as imposed strains in the mesh allowing for consistency of readings (all members of the truss having same stiffness). The performed Demec measurements allow determination of the kinematics of each crack in detail as it is possible to calculate the opening ( $w$, measured along the axis $y^{\prime}$ normal to the crack) and the sliding ( $\Delta$, measured along the axis $x^{\prime}$ tangential to the crack) of each point of the crack based on them. The procedure adopted for this calculation is presented in the Appendix and its results will be presented and discussed in the following.

\section{Analysis of shear-transfer actions}

The investigation of shear-transfer actions at failure is performed by considering the free bodies shown in Figures 4(a)-4(c). The forces potentially acting on them are illustrated in Figure 5. The 

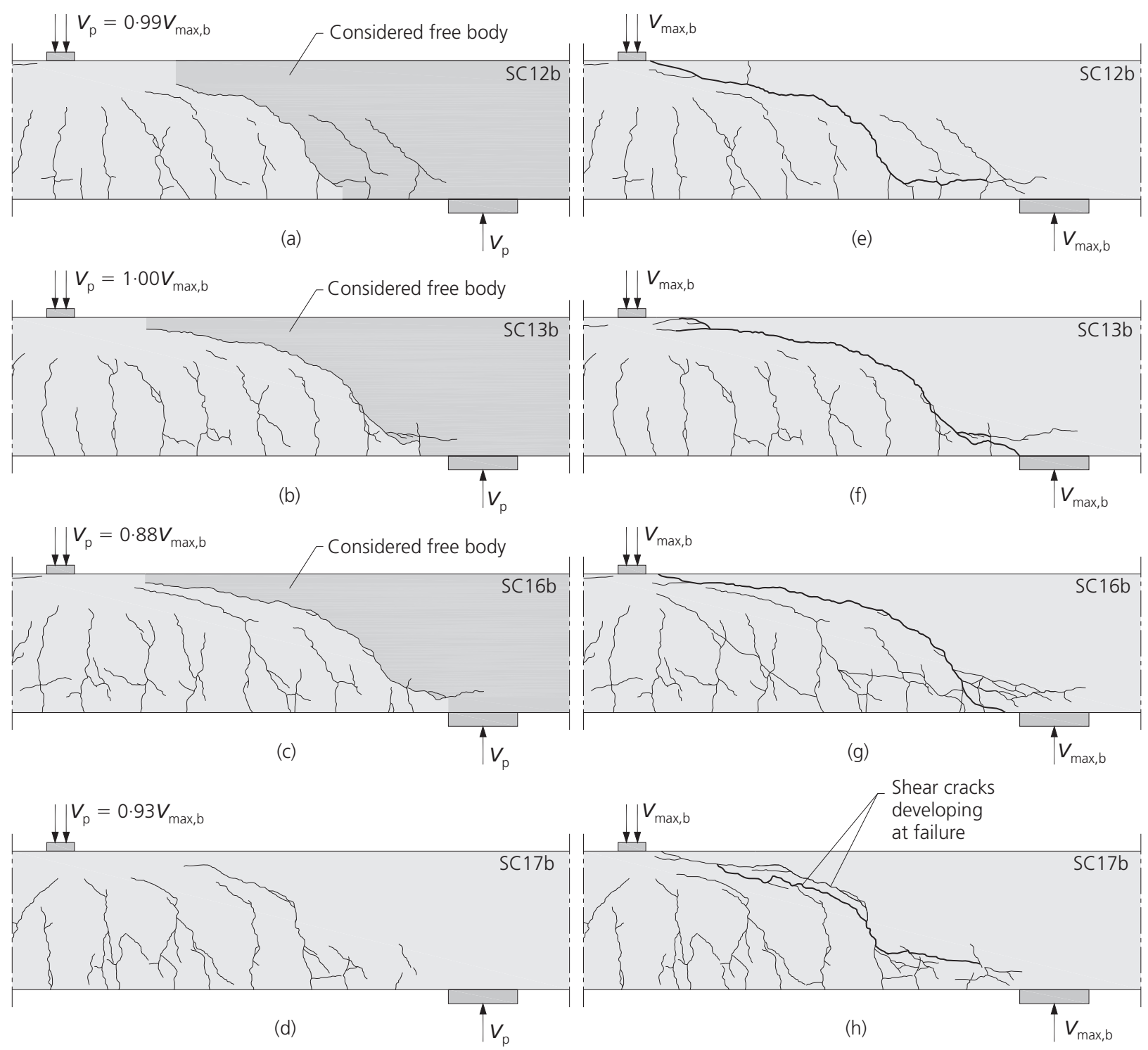

Figure 4. Observed cracking patterns for tests with transversal reinforcements: (a)-(d) at the last measurement step; (e)-(h) at failure

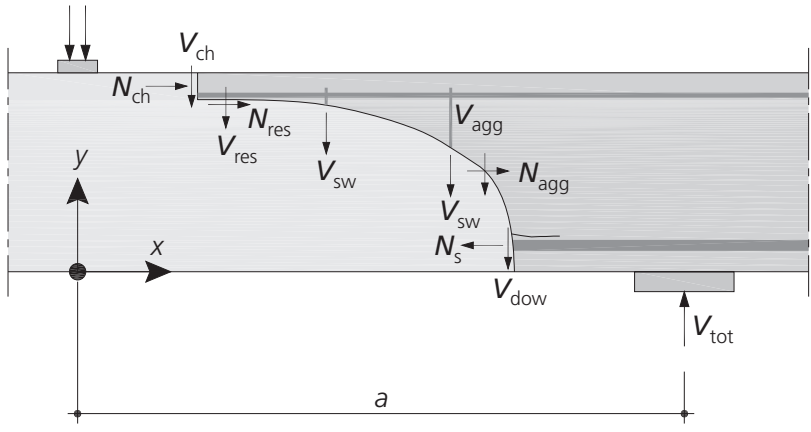

Figure 5. Forces acting on the considered free body defined by the critical shear crack value of each force depends on the actual shape of the critical crack defining the rigid body and on its kinematics. As shown in Figure 5, the total shear force $\left(\boldsymbol{V}_{\text {tot }}\right)$ that can be transferred through the critical crack can be considered to be the sum of

- the vertical component of aggregate interlock action, $\boldsymbol{V}_{\text {agg }}$

- forces developed in the stirrups, $\boldsymbol{V}_{\mathrm{sw}}$

- the vertical component of concrete residual tensile strength, $V_{\text {res }}$

- the dowelling action of the flexural bars, $\boldsymbol{V}_{\text {dow }}$

- the vertical component of the inclined compression chord, $\boldsymbol{V}_{\mathrm{ch}}$.

In addition, the following horizontal forces are also considered to satisfy the equilibrium of the rigid body 
- tension force in the flexural bars, $\boldsymbol{N}_{\mathrm{s}}$

- the horizontal component of aggregate interlock action, $\boldsymbol{N}_{\mathrm{agg}}$

- the horizontal component of the inclined compression chord, $N_{\text {ch }}$

- the horizontal component of the concrete residual tensile strength, $\boldsymbol{N}_{\text {res }}$.

The dowel action of the transverse reinforcement and the inner forces in the compression reinforcement are neglected in this analysis.

The analysis of the inner forces acting on the free bodies is performed by first estimating the aggregate interlock action $\left(\boldsymbol{V}_{\text {agg }}, \boldsymbol{N}_{\text {agg }}\right)$, the shear reinforcements action $\left(\boldsymbol{V}_{\mathrm{sW}}\right)$, the residual tensile strength action $\left(\boldsymbol{V}_{\text {res }}, \boldsymbol{N}_{\text {res }}\right)$ and the dowel action $\left(\boldsymbol{V}_{\text {dow }}\right)$ on the basis of the measured kinematics and by using a number of mechanical models detailed later. Once these actions are determined, forces $N_{\mathrm{s}}$ and $\boldsymbol{N}_{\mathrm{ch}}$ are calculated in order to satisfy both moment and horizontal equilibrium conditions. This may require, if an inclination of the compression chord $\left(\boldsymbol{V}_{\mathrm{ch}}\right)$ is considered, obtaining the result by iterations. In addition, iterations may be required to compute the dowelling force $\left(\boldsymbol{V}_{\text {dow }}\right)$ in the case that the flexural reinforcement yields under the combined action of normal $\left(\boldsymbol{N}_{\mathrm{s}}\right)$ and shear forces $\left(\boldsymbol{V}_{\text {dow }}\right)$.

\section{Aggregate interlock action}

In the literature, many approaches have been proposed to calculate the aggregate interlock stresses based on the relative displacements of the surfaces of a crack. Notable analytical developments were performed in the 1980s by Walraven (1980) and Dei Poli et al. (1987). In this paper, the model proposed by Walraven (1980) is selected due to its generality and physical basis. This model allows association of the relative displacements between the surfaces of a crack (opening $w$ and sliding $\Delta$ ) with the transferred compression $\left(\sigma_{\text {agg }}\right)$ and shear $\left(\tau_{\text {agg }}\right)$ stresses. This allows, by integration of the stresses along the crack surface, calculation of the shear and compression forces $\left(\boldsymbol{V}_{\text {agg }}\right.$ and $\boldsymbol{N}_{\text {agg }}$ ) acting along the crack. The interface stresses are calculated (Walraven, 1980) as

$$
\begin{aligned}
\bar{\sigma}_{\mathrm{agg}} & =\left[\begin{array}{l}
\sigma_{\mathrm{agg}} \\
\tau_{\mathrm{agg}}
\end{array}\right]=\left[\begin{array}{c}
\sigma_{\mathrm{agg}}(w, \Delta) \\
\tau_{\mathrm{agg}}(w, \Delta)
\end{array}\right] \\
& =\left[\begin{array}{l}
\sigma_{\mathrm{pu}} \cdot\left(\bar{A}_{\Delta}-\mu \bar{A}_{w}\right) \geqslant 0 \\
-\sigma_{\mathrm{pu}} \cdot\left(\bar{A}_{w}+\mu \bar{A}_{\Delta}\right)
\end{array}\right]
\end{aligned}
$$

where $\sigma_{\mathrm{pu}}=6.39 f_{\mathrm{c} \text {,cube }}^{0.56}$ is the compressive plastic strength of cement matrix $f_{\text {c,cube }}$ is the concrete compressive strength measured on a cube (in MPa), $\mu=0.4$ is the coefficient of friction, and $\bar{A}_{w}$ and $\bar{A}_{\Delta}$ are the sum of projections $\left(\bar{a}_{w}\right.$ and $\left.\bar{a}_{\Delta}\right)$ of the contact surfaces between aggregates and matrix on both axis normal and tangential to the crack (see Figure 6(a)). Values of $\bar{A}_{w}$ and $\bar{A}_{\Delta}$ are functions of the kinematics of the crack, the maximum aggregate size $\left(d_{\mathrm{g}}\right)$ and the relative aggregate volume fraction $\left(p_{\mathrm{k}}\right)$ (Walraven, 1980). The latter parameter defines the probability that an arbitrary point in the concrete is located inside an aggregate and is thus equal to the ratio between the total volume of the aggregate and the volume of the concrete. This ratio was calculated for both types of concrete (average density of aggregates equal to $2600 \mathrm{~kg} / \mathrm{m}^{3}$ and density of cement equal to $2800 \mathrm{~kg} / \mathrm{m}^{3}$ ) to be $p_{\mathrm{k}}=0.76$ for NSC and $p_{\mathrm{k}}=0.65$ for SCC. It is interesting to note that SCC has a lower value of $p_{\mathrm{k}}$ than NSC, thus leading to a lower interlock contribution for the same kinematics and maximum aggregate size $\left(d_{\mathrm{g}}=16 \mathrm{~mm}\right.$ for the investigated specimens).

With respect to the crack kinematics, Walraven (1980) assumes that all crack opening $(w)$ develops prior to crack sliding $(\Delta)$ (see Figure 6(b)). The crack kinematics adopted by Walraven have been generalised by Guidotti (2010) by accounting only for a fraction of the total crack opening $\left(w_{0}\right)$ developing prior to crack sliding, followed by an increase in both crack opening and sliding (displacement $\delta$ ) at an angle $\gamma$ with respect to the crack plane (see Figures 6(a) and 6(b)). Other kinematics can be found in the scientific literature with application to shear problems (such as Ulaga (2003) where $\left.w_{0}=0, \gamma=\arctan (w / \Delta)\right)$ but these can be considered (as can that of Walraven, $w_{0}=w, \gamma=0$ ) as particular cases of the one proposed by Guidotti (2010).

A comparison of the computed stresses for various kinematics and as a function of crack opening and sliding is shown in Figures 6(c) and 6(d). The kinematics proposed by Walraven (1980) (dashed curves) represent an upper bound of aggregate interlock contribution while those proposed by Ulaga (2003) (dotted curves) represent a lower bound. The kinematics proposed by Guidotti (2010) (continuous curves) generate intermediate stress values.

Using the measured crack shape and kinematics (Figure 7(a)), the interlock stresses $\left(\bar{\sigma}_{\text {agg }}\right)$ can be estimated (Figure $7($ b)). Integration of $\bar{\sigma}_{\text {agg }}$ then yields the vertical and horizontal components of the aggregate interlock forces ( $\boldsymbol{V}_{\text {agg }}$ and $\boldsymbol{N}_{\text {agg }}$, Figure 7(b)). For calculation of the aggregate interlock contribution, the crack shape is approximated by a spline whose key points are spaced at a maximal distance equal to the aggregate size $d_{\mathrm{g}}$. This spline is corrected with additional key points if the distance between the spline and the actual crack becomes larger than half the aggregate size (loss of contact between lips of the crack). This strategy was adopted as Walraven's model (Walraven, 1980) already accounts for the local (micro) roughness of the crack.

With respect to crack kinematics, the approach of Guidotti (2010) was used. A value of $w_{0}$ was calculated for each point of the critical crack in order to obtain the best fit to the measured kinematics (minimum square root criterion, see Figure 6(b)). The obtained results of these calculations are summarised in Table 3. The distributions of the compressive interlock stress and the 


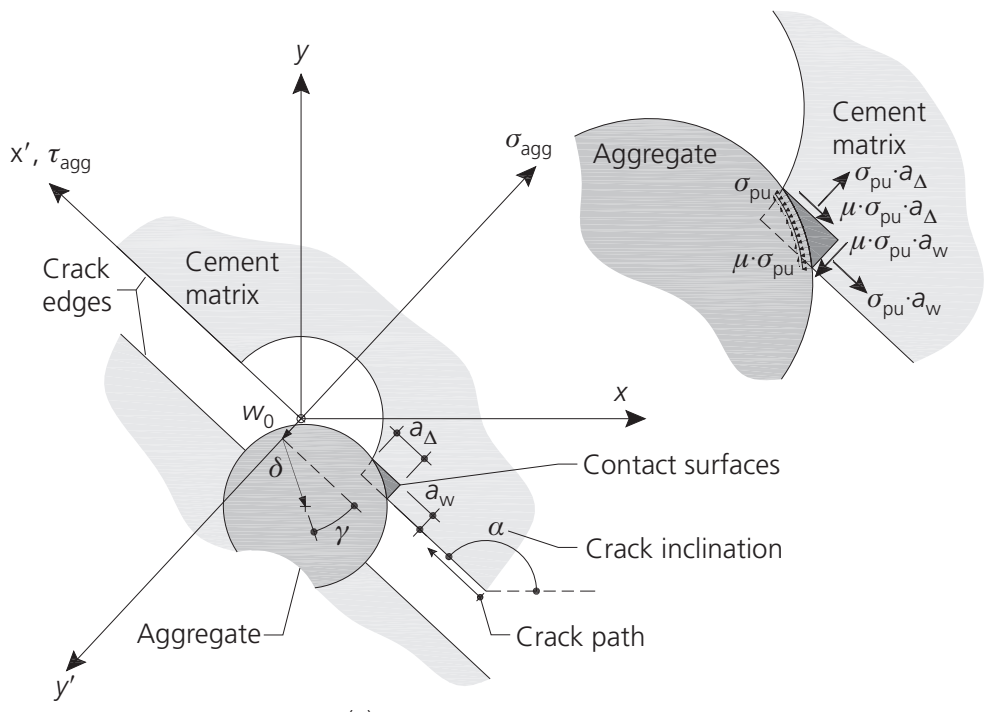

(a)

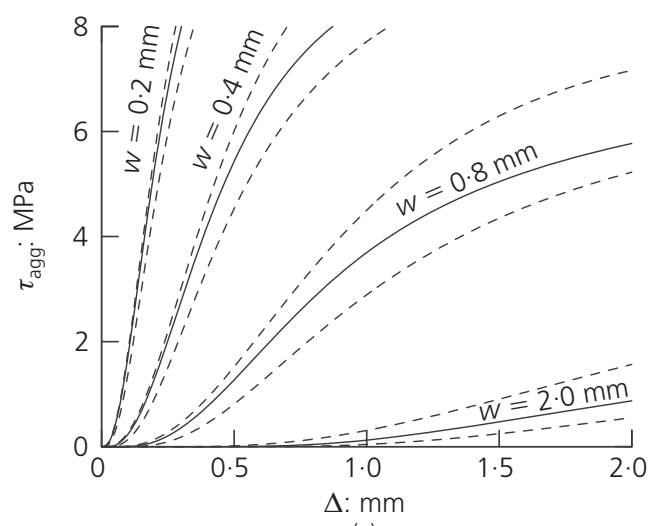

(c)

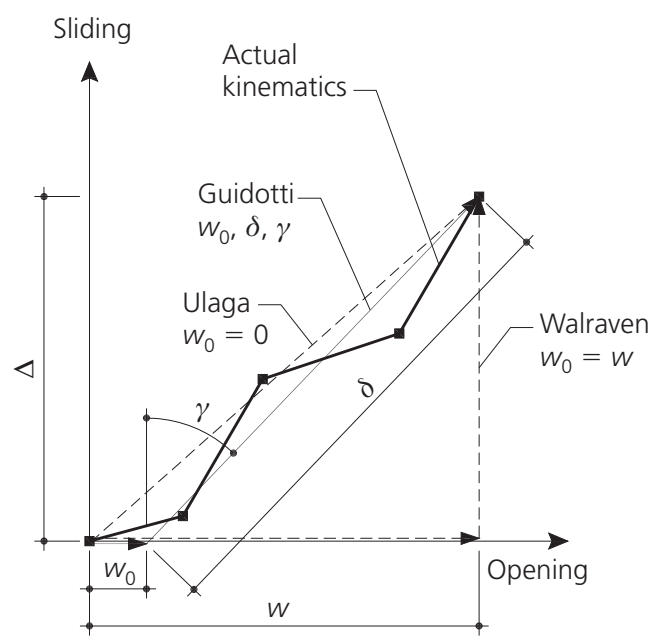

(b)

Figure 6. Aggregate interlock contribution. (a) Contact zone between aggregate and cement matrix and interlock stresses. (b) Crack kinematics (opening and sliding). (c), (d) Tangential and normal interlock stresses according to kinematics proposed by Walraven (1980), Guidotti (2010) and Ulaga (2003) (calculated for $d_{\mathrm{g}}=16 \mathrm{~mm}, p_{\mathrm{k}}=0.75$ and $f_{\mathrm{c}, \text { cube }}=50 \mathrm{MPa}$ )

resulting forces are shown in Figure 7(b). Almost all aggregate interlock action develops in the steepest part of the critical crack, since the measured crack sliding is larger in these regions (see Figure 7(a)). The obtained results differ depending on the shape of the crack, providing a rather high contribution for test $\mathrm{SC} 12 \mathrm{~b}$ (with steeper and curved cracks) and a lower contribution for tests $\mathrm{SC} 13 \mathrm{~b}$ and $\mathrm{SC} 16 \mathrm{~b}$ (flatter and rather linear cracks).

\section{Transversal reinforcement contribution}

For a concrete member provided with stirrups, opening of an inclined shear crack leads to their activation. The stresses that can be mobilised are, however, significantly influenced by the bond and development conditions of the reinforcement (Fernández Ruiz and Muttoni, 2009).

A simple and consistent way to investigate the behaviour of transverse reinforcement embedded in concrete is by assuming rigid-plastic bond behaviour at their interface (see Figure 8(b)). This methodology has been proved to be applicable before and after bar yielding and can be applied to a number of bond-related problems (Fernández Ruiz et al., 2010; Sigrist, 1995) including unloading (Muttoni and Fernández Ruiz, 2007). According to this approach, all tension force is carried by the steel at the location of the cracks and decreases in the regions where it is bonded to 

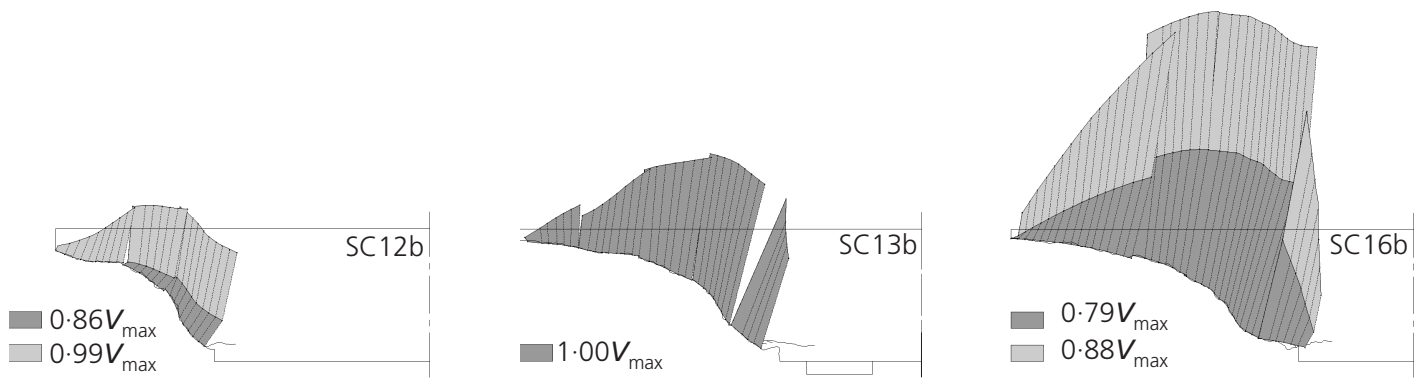

$1 \mathrm{~mm}$

(a)
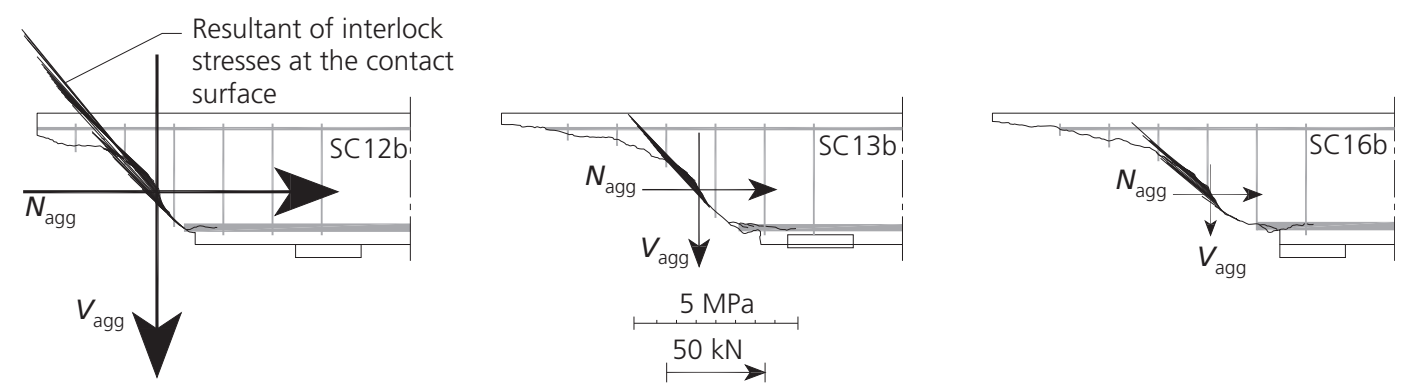

(b)

Figure 7. Application of aggregate interlock model to investigated specimens: (a) observed kinematics; (b) aggregate interlock stresses and forces

concrete. Prior to bar yielding, the bond stress is constant (Sigrist, 1995) $\left(\tau_{\mathrm{b} 0}=2 f_{\mathrm{ct}}\right)$ and thus the decrease of the steel stress (tension stiffening) is linear with the distance to the crack (Figure 8(a)). After bar yielding, plastic strains localise in a zone near the crack where bond stresses are reduced (for tensile forces (Sigrist, 1995) $\tau_{\mathrm{b} 1}=f_{\mathrm{ct}}$; other cases can be found elsewhere (Fernández Ruiz et al., 2007)).

If concrete strains are neglected (in comparison to steel strains), the crack width $\left(w_{i}\right)$ can be obtained by integration of the steel strains

2. $w_{i}=\int_{l_{\mathrm{tot}, i}} \varepsilon_{\mathrm{s}} \mathrm{d} x$

Using this relationship, one can calculate the profile of stresses in a bar for a given crack width (Fernández Ruiz et al., 2007; Sigrist, 1995) (or vice versa). For vertical transverse reinforcement, the shear force carried by a given stirrup $\left(\boldsymbol{V}_{\mathrm{sw} i}\right)$ can be calculated as

3. $\boldsymbol{V}_{\mathrm{sw} i}=\frac{\sigma_{\mathrm{sw}} d_{\mathrm{bw}}^{2} \pi}{4}$

where $\sigma_{\mathrm{sw}}$ is the value of the stress at the location of the crack with a given vertical opening $\left(v_{\mathrm{sw}}\right)$ and $d_{\mathrm{bw}}$ refers to the diameter of the bar (all bars were fully developed in the vertical part of the stirrups; see Figure 2(a)).

In the tests presented here, and accounting for the small diameter of the stirrups $\left(d_{\mathrm{bw}}=6 \mathrm{~mm}\right)$, the properties of the steel used (yield strength $f_{\mathrm{yw}}=497 \mathrm{MPa}$, measured tensile strength $f_{\mathrm{tw}}=595 \mathrm{MPa}$, modulus of elasticity $E_{\mathrm{sw}}=205 \mathrm{GPa}$ and hardening modulus calculated as the slope of the stress-strain diagram between failure and yielding, $E_{\text {shw }}=1560 \mathrm{MPa}$ ) and the concrete tensile strength $\left(f_{\text {ct }}=3 \mathrm{MPa}\right.$ ), it can be noted (see Figure $8(\mathrm{c})$ ) that even a small crack opening of $v_{\mathrm{swy}} \approx 0.3 \mathrm{~mm}$ is sufficient to yield the bar. Tensile rupture occurs theoretically for a larger opening $\left(v_{\text {swt }} \approx 3.4 \mathrm{~mm}\right)$, but is still limited.

Calculation of the contribution of the stirrups to the shear strength for the specimens investigated in this paper was performed on the basis of the measured crack widths and crack locations. For each stirrup, the locations at which it is intercepted by cracks are determined along with their vertical openings (openings along the axis of the stirrup), taking advantage of the Demec measurements. On that basis, and accounting for the bond model previously introduced, the stresses and forces of the stirrups are determined. The obtained results of these calculations are summarised in Table 3 (sum of contribution of each stirrup). The resulting forces are shown in Figure 8(d). For this action, the results again depend strongly on the crack shape and kinematics 
(opening). The efficiency of the stirrups is nevertheless opposite that of the aggregate interlock as flatter cracks ( $\mathrm{SC} 13 \mathrm{~b}$ and $\mathrm{SC16b}$ ) intercept a larger number of stirrups, leading to larger contributions. It can be noted that for test $\mathrm{SC} 16 \mathrm{~b}$, the stirrup closest to the support plate is not accounted for because it is intercepted by a horizontal branch of the crack and will thus be considered (as will be explained later) as a dowelling contribution.

\section{Concrete residual tensile strength contribution}

As shown by Hillerborg (1983), after the development of a crack, concrete exhibits a softening residual strength $\left(\sigma_{\text {res }}\right)$. In the fracture process zone (FPZ) (Hillerborg, 1983), this residual strength allows the transfer of forces through the crack. The vertical component of this force for beams $\left(\boldsymbol{V}_{\text {res }}\right)$ can thus transfer a certain amount of shear and the horizontal component of this force $\left(\boldsymbol{N}_{\text {res }}\right)$ is to be considered in the equilibrium of forces acting on the free body.

The concrete softening behaviour can be modelled using a number of approaches (fib, 2011; Hordijk, 1992). In this paper the proposal of Hordijk (1992) (which shows good correlation with the behaviour of NSC) is used. Figure 9(a) shows the relationship between the residual tensile strength $\left(\sigma_{\text {res }}\right)$ and the crack opening $(w)$, which is defined by

$$
\begin{aligned}
\sigma_{\text {res }}=f_{\text {ct }} & {\left[\left(1+\left(c_{1} \frac{w}{w_{\mathrm{c}}}\right)^{3}\right) \mathrm{e}^{-c_{2}\left(w / w_{\mathrm{c}}\right)}\right.} \\
& \left.-\frac{w}{w_{\mathrm{c}}}\left(1+c_{1}^{3}\right) \mathrm{e}^{-c_{2}}\right]
\end{aligned}
$$

where $w_{\mathrm{c}}=5 \cdot 14\left(G_{\mathrm{F}} / f_{\mathrm{ct}}\right)$ represents the maximum crack width for stress transfer and $c_{1}(=3.0)$ and $c_{2}(=6.93)$ are constants of the model (Hordijk, 1992). For calculation of the fracture energy $G_{\mathrm{F}}$, the proposal of Model Code 2010 (fib, 2011) was used: $G_{\mathrm{F}}=73 f_{\mathrm{c}}^{0.18}$, where $f_{\mathrm{c}}$ is the concrete compressive strength in $\mathrm{MPa}$.

It should be noted that the detrimental influence of the compression stresses developing in the investigated region (compression chord of the member) on the tensile strength of concrete (Kupfer et al., 1969) is neglected (this assumption will be discussed later). The input data used to apply this model are the measured openings $(w)$ of the crack at each point of the critical crack (see Figure 9(b)). Unfortunately, no valid measurements were available for test $\mathrm{SC} 16 \mathrm{~b}$ in this zone (where $w<w_{\mathrm{c}}$; see Figure 9(b)) and the analysis is thus limited to tests $\mathrm{SC} 12 \mathrm{~b}$ and $\mathrm{SC} 13 \mathrm{~b}$.

The results of these calculations are shown in Table 3 and the resulting stresses and forces are shown in Figure 9(c). It can be seen that, due to the size of the members and values of crack widths, the residual tensile strength has a rather low contribution 


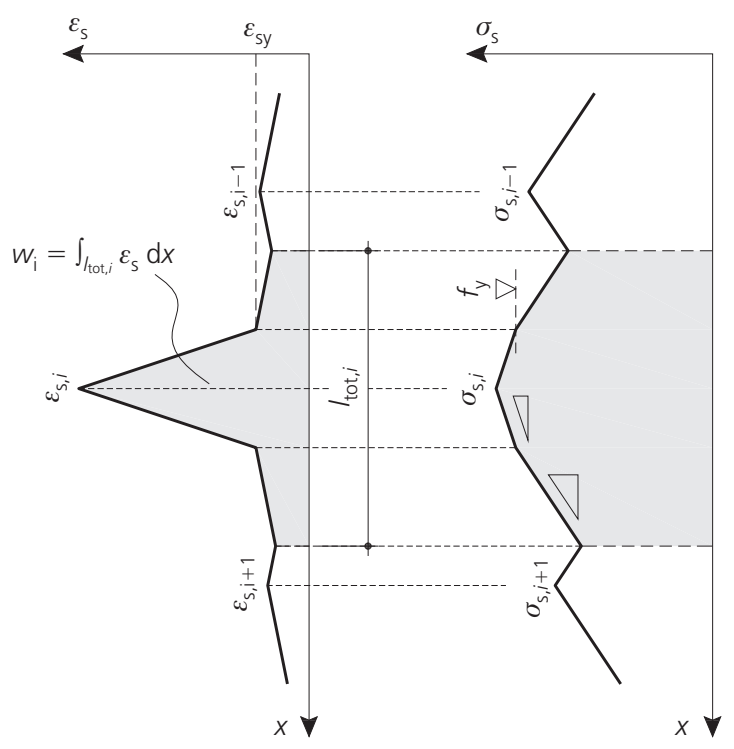

(a)
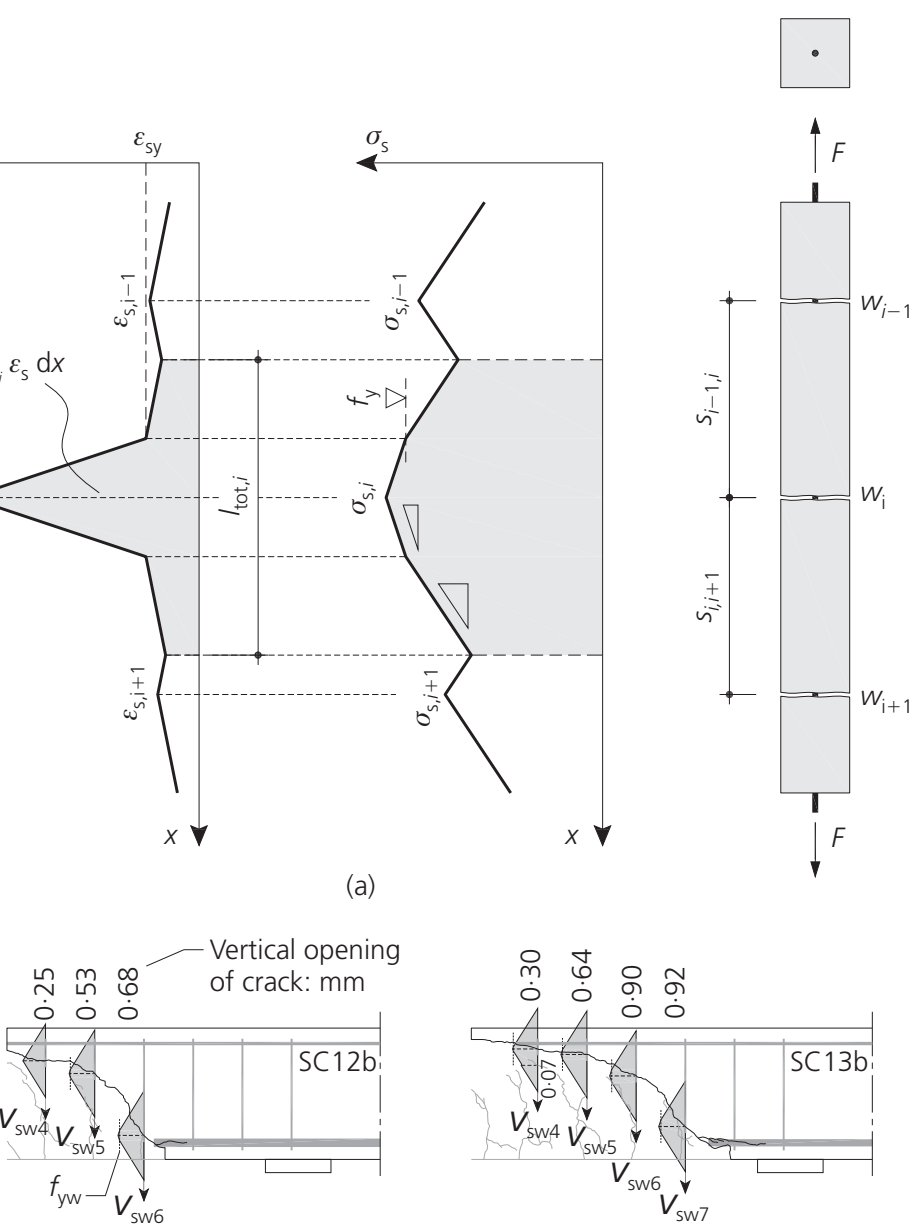

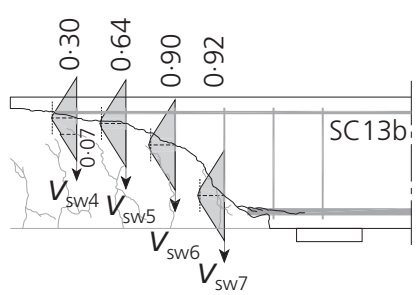

$\stackrel{1 \mathrm{GPa}}{\stackrel{25 \mathrm{kN}}{2}}$

(d)

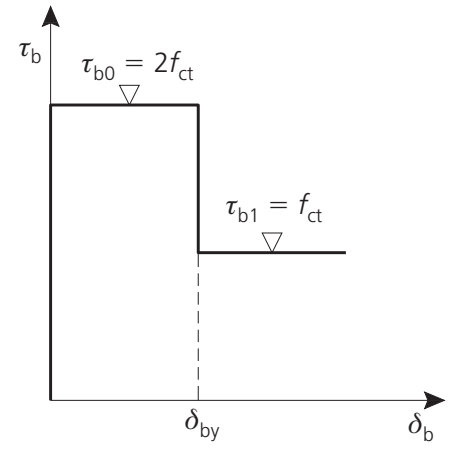

(b)

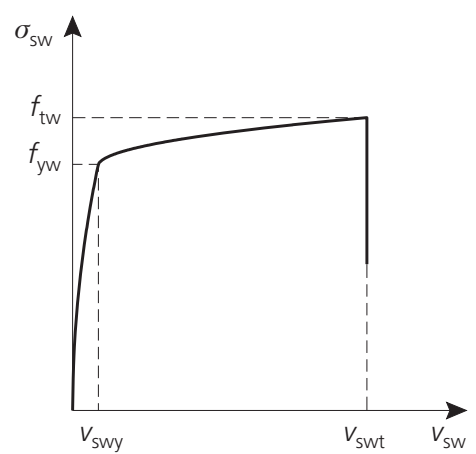

(c)

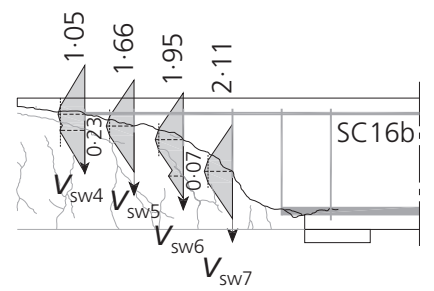

Figure 8. Transverse reinforcement contribution. (a) Relationship between cracks opening and steel strain and stresses in a RC tie. (b) Assumed rigid-plastic bond behaviour. (c) Behaviour of an embedded (bonded) vertical stirrup. (d) Application to investigated specimens: observed kinematics, calculated stresses and transferred shear forces

to shear strength. When the detrimental influence of the compressive stresses on tensile strength is accounted for, its contribution will even be lower. For thinner specimens (thus developing smaller crack widths) the contribution of this action may be more significant.

\section{Dowelling action of flexural reinforcement}

Another action reported in the scientific literature is the dowelling strength provided by flexural bars (Chana, 1987; Dei Poli et al., 1992, 1993; Jelic et al., 1999; Krefeld and Thurston Charles, 1966a, 1966b; Paulay et al., 1974; Taylor, 1969; Zararis, 2003). This action depends mostly on the diameter of the flexural bars, the presence of transverse reinforcement, the concrete cover and its strength, and the distance of the critical shear crack to the support plate. Despite the significant number of studies performed in this field, a numerical model (see Figure 10(a)) has been specifically developed by the authors to investigate this action. The model allows accounting for the distance of the critical shear crack to the edge of the support and for the actual location and behaviour (elastic-plastic bonded, see Figure 10(b)) of the stirrups as well as for the elastic-plastic behaviour of the flexural bar.

The numerical model corresponds to a cohesive crack model accounting for the residual tensile strength of concrete and the 


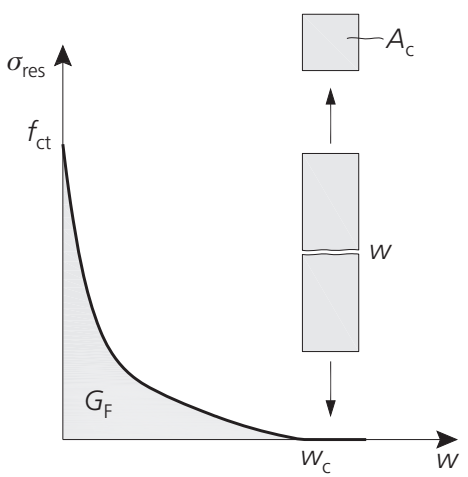

(a)
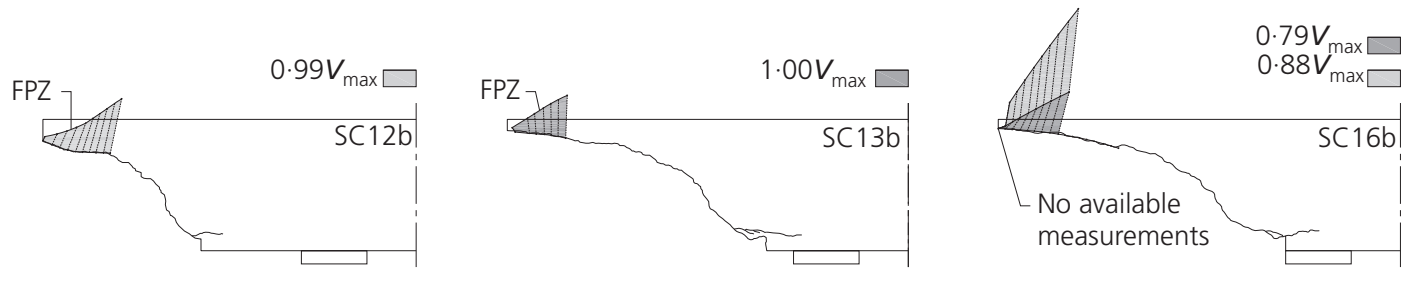

$1 \mathrm{~mm}$

(b)
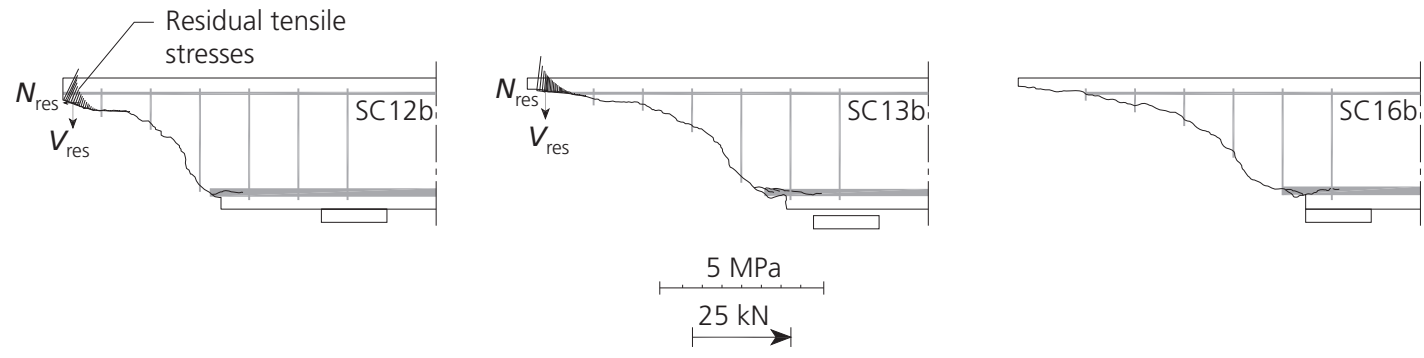

(c)

Figure 9. Residual tensile strength contribution. (a) Tensile softening behaviour of concrete (relationship between crack opening and concrete tensile residual strength in a concrete tie). Application to investigated specimens: (b) observed kinematics in the FPZ; (c) calculated residual tensile stresses and forces

location of the support and the transverse reinforcement (Figure 10(a)). The bar is dowelled according to the measured location of the critical shear crack (when it intercepts the level of the flexural reinforcement), and its relative vertical displacement $\left(v_{\text {dow }}\right)$ is obtained from the Demec measurements (Figure 10(a)). Concrete is simulated through non-linear springs (accounting for their tributary area) reproducing concrete behaviour before and after cracking (for the latter following the FPZ approach; see Figure 10(c)). Stirrups are also simulated as non-linear springs, reproducing the elastic and plastic bonded behaviour of the bar. Typical dowelling curves obtained using this approach are shown in Figure 11 (corresponding to $v_{\text {dow }}=0.5 \mathrm{~mm}$ ). This figure shows that the parameter most influencing the response is the distance from the critical shear crack to the edge of the support plate $\left(L_{\mathrm{dow}}\right)$. The stirrups also show a certain contribution, although it is secondary with respect to the crack location.
Figure 10(d) shows a summary of the recorded values for $v_{\text {dow }}$ and $L_{\mathrm{dow}}$ for the various specimens of the experimental programme. On that basis, the dowelling action can be calculated (see Table 3). The results show a significant dependency on the location of the crack. Thus, for test SC12b, where the crack is far from the support plate and first intercepted stirrup, this action is almost negligible. On the contrary, for test $\mathrm{SC} 13 \mathrm{~b}$ and particularly for test $\mathrm{SC} 16 \mathrm{~b}$, the crack develops close to the bearing plate and the shear force that can be transferred through dowelling action becomes very significant.

\section{Contribution of inclined compression chord}

Another potential action for carrying shear forces is the inclination of the compression chord ( $\boldsymbol{V}_{\text {ch }}$; see Figure 12(a)). This is shown in Figures 12(b) and 12(c) where two truss models are presented (Leonhardt and Mönnig, 1974). The first (Figure 12(b)) 

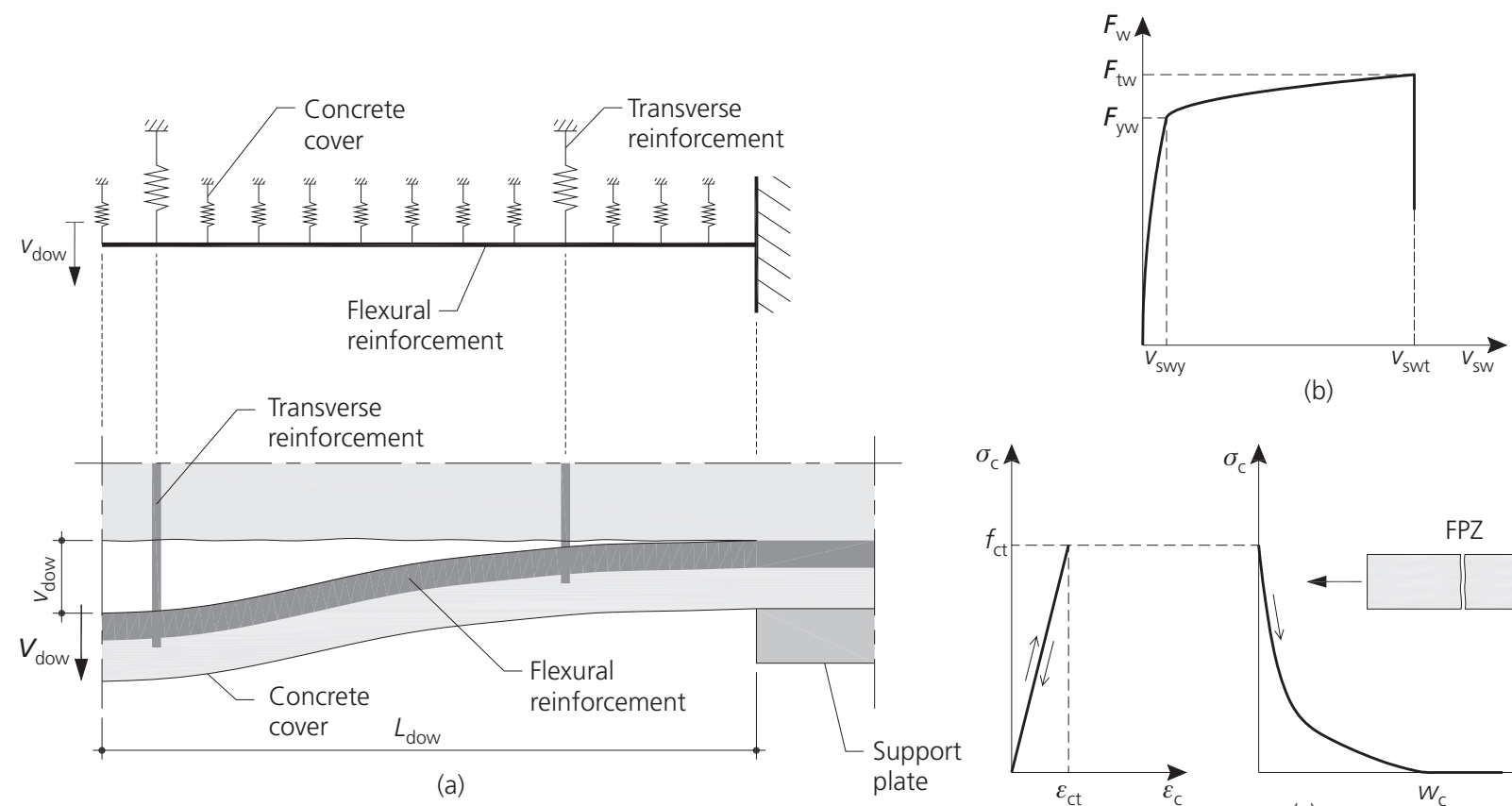

(b)
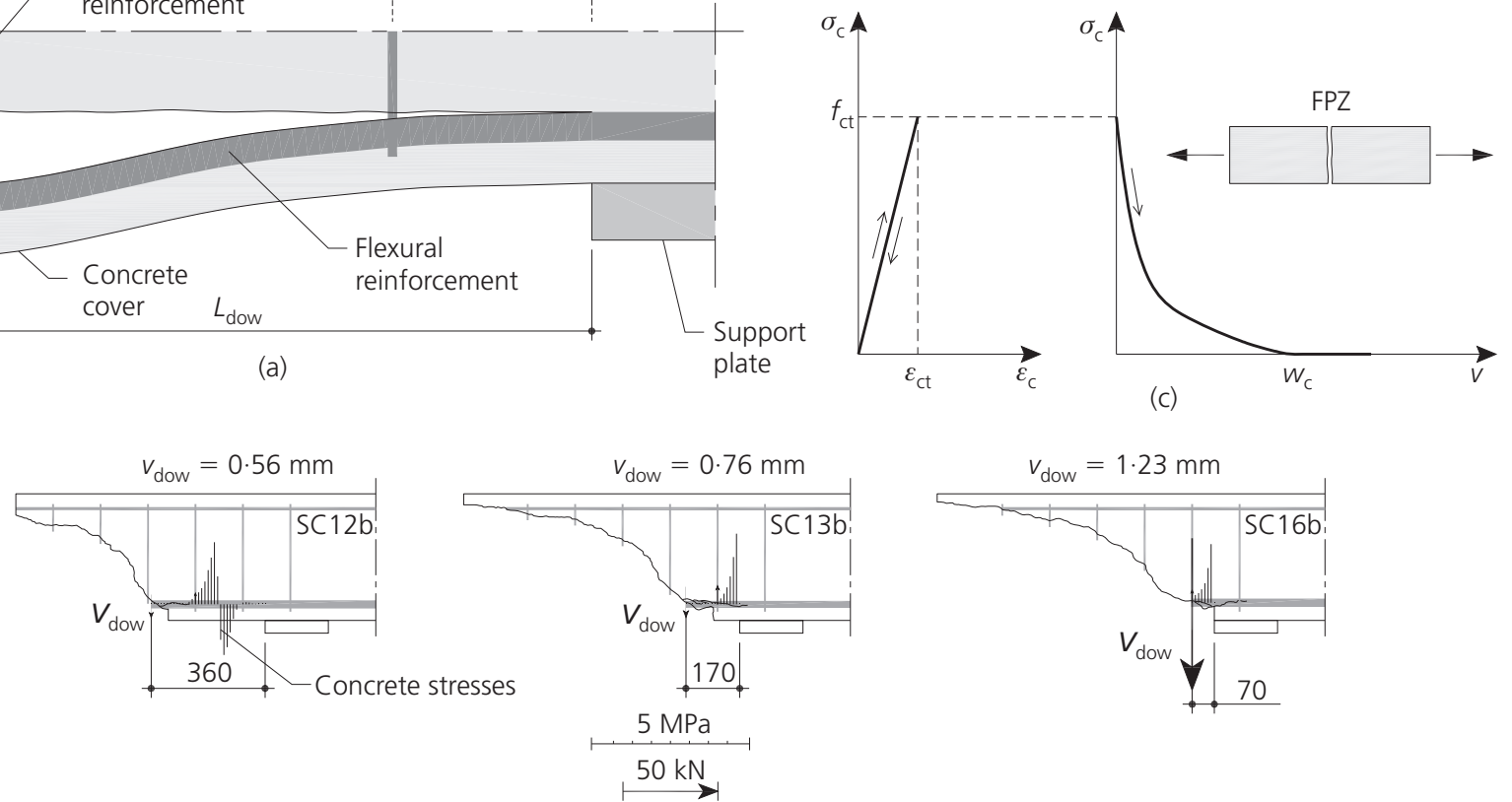

(c)

(d)

Figure 10. Flexural reinforcement contribution (dowel action).

(a) Cohesive crack modelling. (b) Force-displacement behaviour assumed for transverse reinforcement. (c) Assumed tensile behaviour of concrete cover. (d) Application to investigated specimens: measured kinematics and calculated dowelling forces for tests SC12b, SC13b and SC16b

has both flexural chords (in compression and tension) parallel. Thus, all the shear force is transferred by means of the inclined struts of the web in equilibrium with the transverse reinforcement. As a consequence, the forces in the compression and tension flexural chords decrease with distance to the loading point. Other equilibrium solutions are possible, implying inclination of the compression chord $\left(\alpha_{\mathrm{ch}}\right.$; Figure 12(c)). In this case, a fraction of the shear force is carried by the compression chord ( $V_{\text {ch }}=N_{\text {ch }} \tan \alpha_{\text {ch }}$ ) and the stirrups and web struts only have to equilibrate the remaining part. In this case, the flexural lever arm diminishes and the forces to be carried by the flexural chords increase with respect to those of Figure 12(b).

By detailed analysis of the cracking pattern of the investigated specimens, for tests SC13b and SC16b, the thickness of the compression zone is rather limited - $37 \mathrm{~mm}$ for SC13b (Figure 4(c)) and $28 \mathrm{~mm}$ for SC16b (Figure 4(e)) - and is followed by a quasi-horizontal crack approximately at the level of the compression reinforcement. This implies that the amount of shear that can be transferred by an inclined compression strut should also be somewhat limited and can be neglected. The potential dowelling force of the compression reinforcement also seems to be negligible, accounting for the significant distance between the tip of the quasi-horizontal crack and the loading plate as well as the small diameter $(10 \mathrm{~mm})$ of the compression bars.

For test SC12b, the thickness of the compression zone and the slope of the critical shear crack in the investigated region $(72 \mathrm{~mm})$ are larger. This indicates that this action could potentially be more significant for this specimen. However, the still 


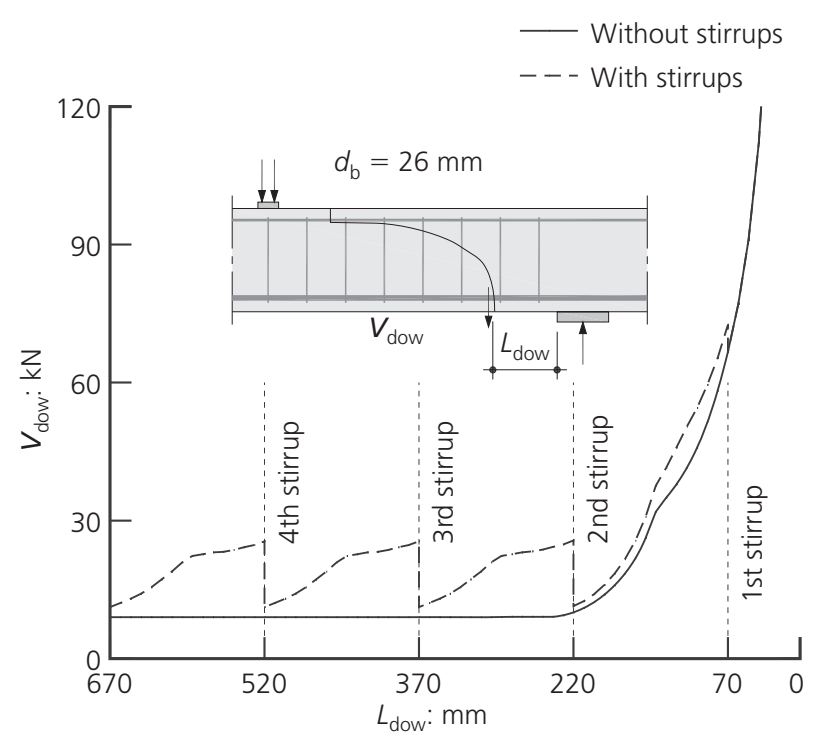

Figure 11. Flexural reinforcement contribution (dowel action): relationship between the dowel shear force $\left(V_{\text {dow }}\right)$ and the distance of the critical shear crack to the edge of the support $\left(L_{\text {dow }}\right)$ calculated for a nominal beam $\left(b=300 \mathrm{~mm}, d_{\mathrm{b}}=26 \mathrm{~mm}\right.$ (three bars), $f_{\mathrm{ct}}=3 \mathrm{MPa}, f_{\mathrm{c}}=40 \mathrm{MPa}, f_{\mathrm{y}}=580 \mathrm{MPa}$,

$E_{\mathrm{s}}=205 \mathrm{GPa}, d_{\mathrm{bw}}=6 \mathrm{~mm}, f_{\mathrm{yw}}=500 \mathrm{MPa}, E_{\mathrm{swh}}=1560 \mathrm{MPa}$ ) subjected to constant constrained displacements $v_{\text {dow }}=0.5 \mathrm{~mm}$ and tensile force $N_{s}=300 \mathrm{kN}\left(\sigma_{\mathrm{s}}=188 \mathrm{MPa}\right)$

limited depth of the investigated region compared to the measurement grid (Figure 2(a)) does not allow for sufficiently detailed measurements to estimate this effect suitably and thus, for this test, the potential contribution of the compression chord to the shear strength will not be calculated.

\section{Discussion of results}

Figure 13 and Table 3 show all contributions for the three investigated specimens as well as the horizontal forces required to satisfy equilibrium conditions. A very reasonable agreement between the sum of the estimated contributions $\left(\boldsymbol{V}_{\text {tot }}\right)$ and the acting shear load $\left(\boldsymbol{V}_{\mathrm{p}}\right)$ is observed, with only a moderate overestimation for test $\mathrm{SC} 12 \mathrm{~b}$. The difference for this latter specimen could be due to an overestimate of the aggregate interlock action, as Walraven's model is quite sensitive for rather steep slopes (crack kinematics).

Interesting results can be obtained by analysis and comparison of the results for the various shear-carrying actions in the three specimens (Figure 14).

- The significance of the various actions is different for each specimen. This is explained by the quite different crack shapes (Figure 3(f)) and measured kinematics (Figure 7(a)).

- Aggregate interlock action is dominant (72\%) for test $\mathrm{SC} 12 \mathrm{~b}$ and still quite significant (44\%) for test SC13b. On the contrary, the wide opening and rather linear shape of the

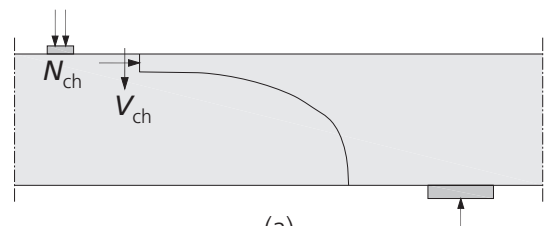

(a)

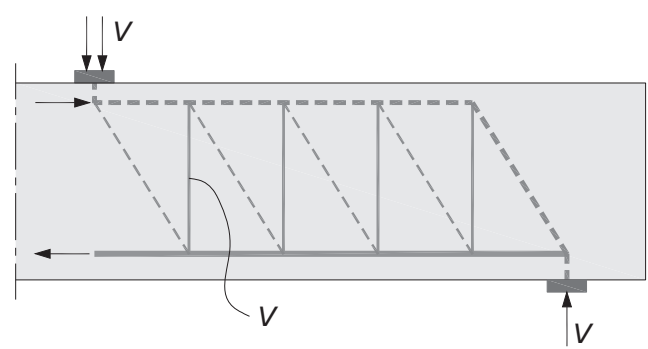

(b)

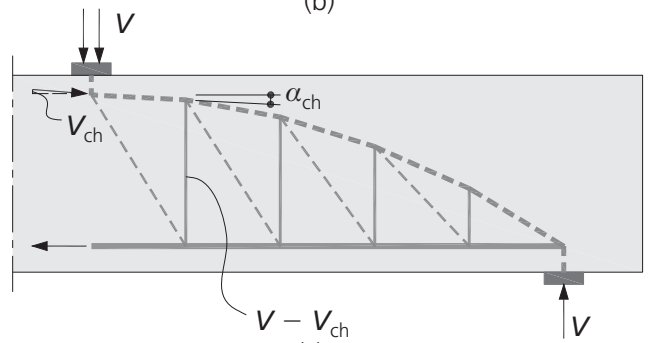

(c)

Figure 12. Inclined compression strut contribution. (a) Definition of the shear and normal forces. Suitable strut-and-tie models for RC members with transversal reinforcements with horizontal compression strut (c) and with inclined compression strut (c)

critical shear crack implies that this contribution is very limited (20\%) for test SC16b.

- Dowelling action is most significant for test SC16b (45\%) due to the limited distance between the critical shear crack and the edge of the support. For crack geometries where aggregate interlock action is more active (steeper cracks and thus at larger distances from the edge of the support), this contribution decreases and is almost negligible (5\% and 10\% for tests $\mathrm{SC} 12 \mathrm{~b}$ and $\mathrm{SC} 13 \mathrm{~b}$, respectively).

- Transverse reinforcement allows the carrying of a significant fraction of the total shear force. The amount depends on the crack shape and is higher for flat cracks intercepting a larger number of stirrups (38\% and 35\% for tests SC13b and SC16b, respectively) than for steep cracks ( $18 \%$ for test $\mathrm{SC} 12 \mathrm{~b})$.

- The residual tensile strength of concrete shows a rather limited contribution for the investigated members. This is mostly due to the crack widths and size of the members.

- The inclination of the compression chord also seems to be of secondary significance for tests SC13b and SC16b. For test $\mathrm{SC} 12 \mathrm{~b}$, no measurements are available to estimate this action suitably.

As has been demonstrated, the critical shear crack shape and its kinematics (opening and sliding) may differ notably (see Figure 7(a)). This potentially leads to different amounts of shear that can 


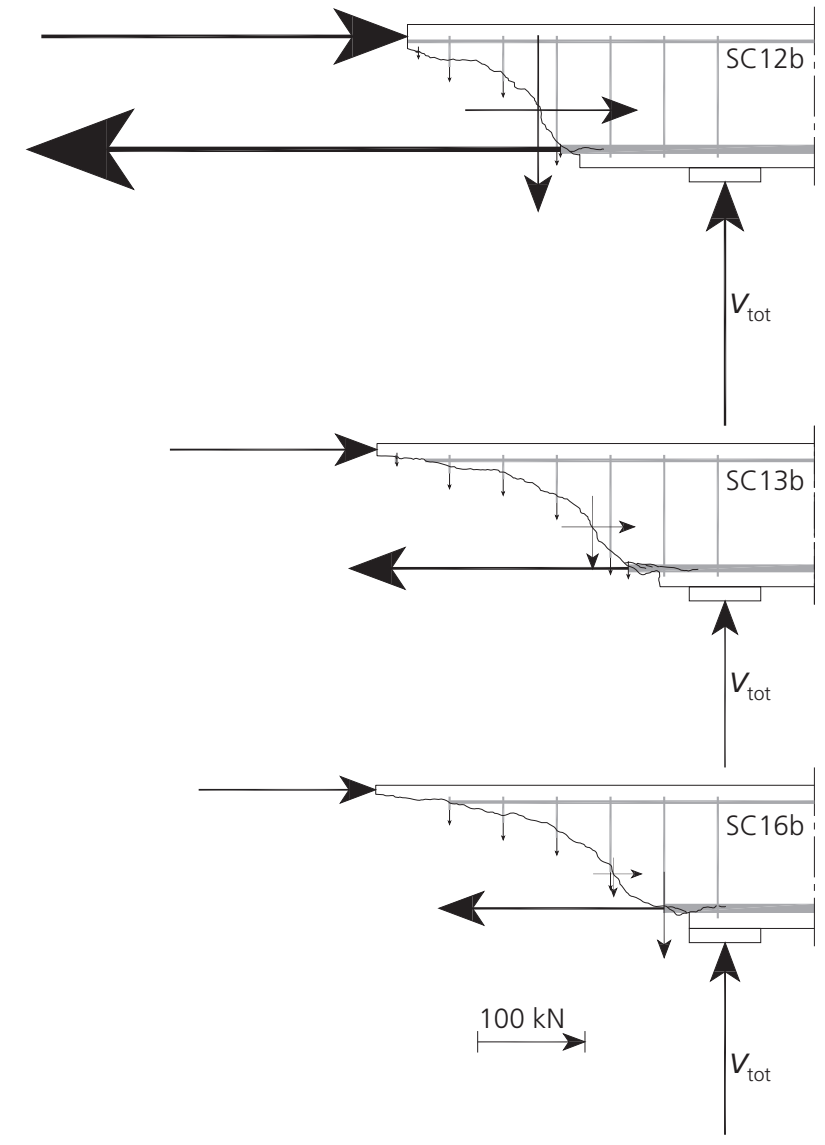

Figure 13. Forces acting on the free bodies

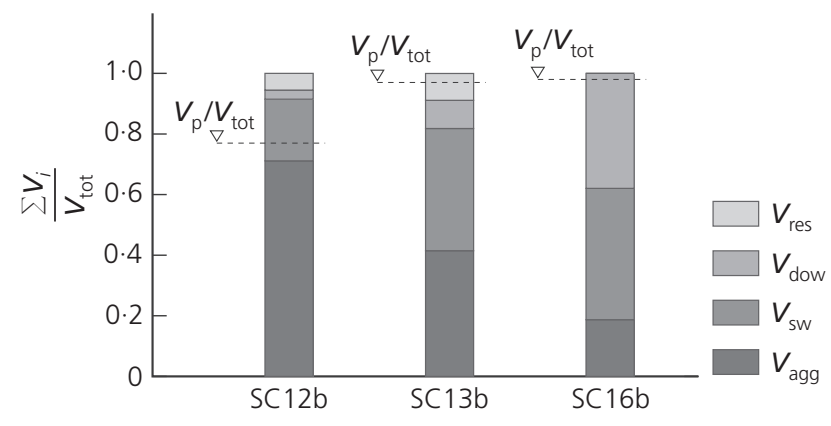

Figure 14. Amount of shear carried by each shear-transfer action

be carried by each shear-transfer action. However, the results are somewhat compensated - for flatter cracks with lower aggregate interlock action, the dowelling and stirrups contributions increase. For members without transverse reinforcement, the aggregate interlock action is thus expected to be dominant as the stirrup contribution is not available and the dowelling action is reduced (refer to Figure 11 and to the crack patterns in Figure 3(e), in agreement with some theoretical works (Muttoni and Fernández Ruiz, 2008)).

\section{Conclusions}

This work investigated the shear transferred in one-way reinforced concrete members with small amounts of transverse reinforcement. A number of analyses have been performed on the basis of detailed measurements of cracking patterns and actual kinematics at failure of three beams. The main conclusions are as follows.

- The amount of shear transferred by the various potential actions (aggregate interlock, transverse reinforcement, residual tensile strength, dowelling action, inclination of compression chord) is highly dependent on the shape and associated kinematics of the critical shear crack, which may significantly vary for members with low transverse reinforcement.

- The amount of shear carried by each action can be suitably investigated on the basis of refined kinematical measurements and by using mechanical models describing the local transfer of shear forces.

- For the investigated specimens, almost all shear force is carried by a combination of aggregate interlock, dowelling action and stirrup contribution. The rest of the actions are negligible. For geometries or sizes different to those investigated here, other actions (such as the residual tensile strength or the compression zone) may, however, become more significant.

- Aggregate interlock is dominant for steep critical shear cracks, whereas dowelling and stirrup contributions are dominant for flat cracks. However, the sum of the various contributions leads to similar strength results.

- For members without transverse reinforcement, the aggregate interlock action is expected to be dominant as the stirrup contribution is not available and dowelling action is reduced.

\section{Appendix}

The measurements performed allow determination of the kinematics of each crack. This can be performed, as shown in Figure 15 , by calculating the displacement fields of two rigid bodies located at both sides of the investigated crack $\left(w_{1}(x, y)\right.$ and $w_{2}(x$, $y)$ ). Each displacement field was calculated by using the measured coordinates of a couple of targets (P1-P2 for the first crack's side and P3-P4 for the second side) of the Demec grid. The displacement of each target is described by both the undeformed position $\left(\mathrm{P} 1^{0}, \mathrm{P} 2^{0}, \mathrm{P} 3^{0}, \mathrm{P} 4^{0}\right)$ and the deformed position at a given load step ( $\left.\mathrm{P} 1^{\text {def }}, \mathrm{P} 2{ }^{\text {def }}, \mathrm{P} 3{ }^{\text {def }}, \mathrm{P} 4{ }^{\text {def }}\right)$

5a. $\quad w_{1}(x, y)=\left\{\begin{array}{l}a_{1}-e_{1} \cdot x \\ b_{1}+e_{1} \cdot y\end{array}\right.$

5b. $w_{2}(x, y)=\left\{\begin{array}{l}a_{2}-e_{2} \cdot x \\ b_{2}+e_{2} \cdot y\end{array}\right.$ 


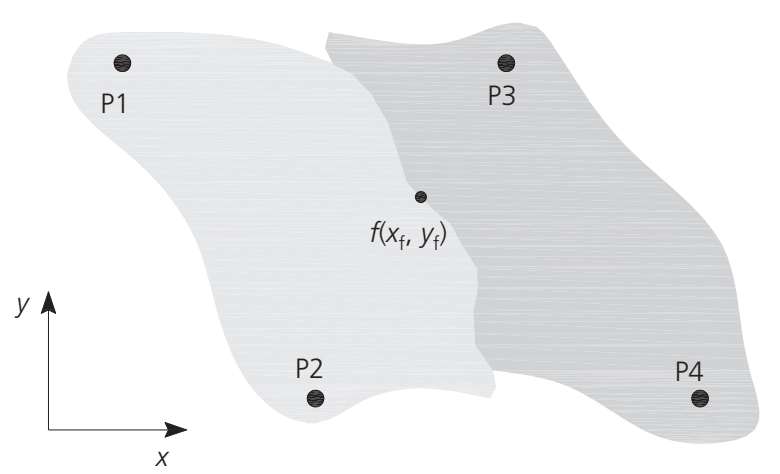

(a)

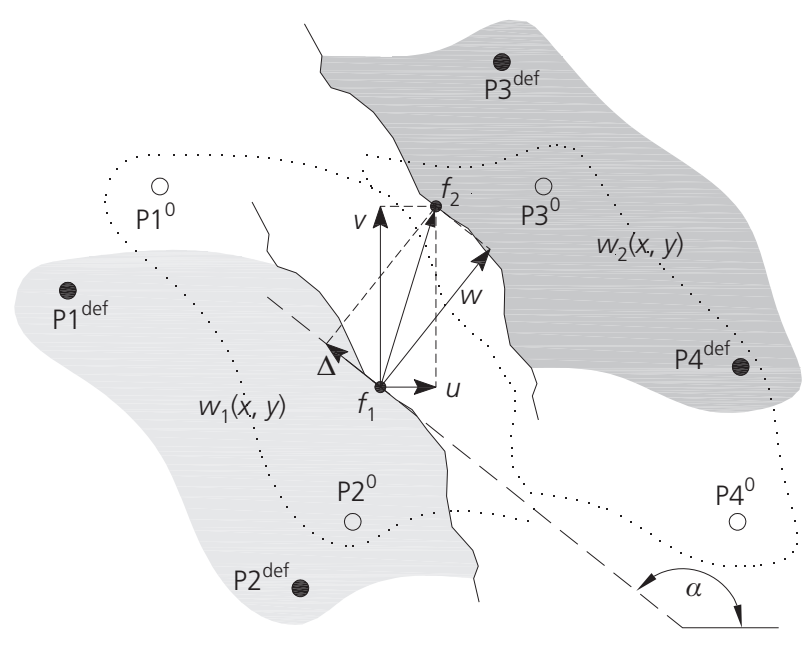

(b)

Figure 15. Measurements for calculation of crack kinematics: (a) undeformed configuration; (b) deformed configuration

where

6a. $\left[\begin{array}{l}a_{1} \\ b_{1} \\ e_{1}\end{array}\right]=\left(\boldsymbol{A}_{1}^{\mathrm{T}} \cdot \boldsymbol{A}_{1}\right)^{-1} \cdot\left(\boldsymbol{A}_{1}^{\mathrm{T}} \cdot \boldsymbol{c}_{1}\right)$

6b. $\quad\left[\begin{array}{l}a_{2} \\ b_{2} \\ e_{2}\end{array}\right]=\left(\boldsymbol{A}_{2}^{\mathrm{T}} \cdot \boldsymbol{A}_{2}\right)^{-1} \cdot\left(\boldsymbol{A}_{2}^{\mathrm{T}} \cdot \boldsymbol{c}_{2}\right)$

and

$7 a$.

$$
\boldsymbol{A}_{1}=\left[\begin{array}{ccc}
1 & 0 & -\mathrm{P} 1_{y}^{0} \\
0 & 1 & \mathrm{P} 1_{x}^{0} \\
1 & 0 & -\mathrm{P} 2_{y}^{0} \\
0 & 1 & \mathrm{P} 2_{x}^{0}
\end{array}\right]
$$

7b. $\quad \boldsymbol{A}_{2}=\left[\begin{array}{ccc}1 & 0 & -\mathrm{P} 3_{y}^{0} \\ 0 & 1 & \mathrm{P} 3_{x}^{0} \\ 1 & 0 & -\mathrm{P} 4_{y}^{0} \\ 0 & 1 & \mathrm{P} 4_{x}^{0}\end{array}\right]$

7c. $\quad \boldsymbol{c}_{1}=\left[\begin{array}{l}\mathrm{P} 1_{x}^{\text {def }}-\mathrm{P} 1_{x}^{0} \\ \mathrm{P} 1_{y}^{\text {def }}-\mathrm{P} 1_{y}^{0} \\ \mathrm{P} 2_{x}^{\text {def }}-\mathrm{P}_{x}^{0} \\ \mathrm{P} 2_{y}^{\text {def }}-\mathrm{P} 2_{y}^{0}\end{array}\right]$

7d. $\quad \boldsymbol{c}_{2}=\left[\begin{array}{c}\mathrm{P} 3_{x}^{\text {def }}-\mathrm{P} 3_{x}^{0} \\ \mathrm{P} 3_{y}^{\text {def }}-\mathrm{P} 3_{y}^{0} \\ \mathrm{P} 4_{x}^{\text {def }}-\mathrm{P} 4_{x}^{0} \\ \mathrm{P} 4_{y}^{\text {def }}-\mathrm{P} 4_{y}^{0}\end{array}\right]$

The relative displacement $\bar{u}=\left[\begin{array}{l}u \\ v\end{array}\right]$ between two points of the crack $f_{2}$ and $f_{1}$, for which the initial position $f\left(x_{f}, y_{f}\right)$ is the same, can be calculated as the difference between the two displacement fields

8. $\quad \bar{u}=\left[\begin{array}{l}u \\ v\end{array}\right]=w_{2}\left(x_{f}, y_{f}\right)-w_{1}\left(x_{f}, y_{f}\right)$

This method requires that the zone delimited by the four Demec targets (see Figure 15) is crossed by a single crack. Once the relative displacement $(\bar{u})$ is known, the opening ( $w$, measured along the axis $y^{\prime}$ normal to the crack) and the sliding ( $\Delta$, measured along the axis $x^{\prime}$ tangential to the crack) at a given point of the crack with inclination $\alpha$ can also be calculated as

9. $\quad \bar{w}=\left[\begin{array}{l}\Delta \\ w\end{array}\right]=\left[\begin{array}{ll}\cos \alpha & \sin \alpha \\ -\sin \alpha & \cos \alpha\end{array}\right] \cdot \bar{u}$

\section{REFERENCES}

ACI (American Concrete Institute) (2008) ACI 318-08: Building code requirements for structural concrete. ACI, Detroit, MI, USA.

Bažant ZP and Kazemi T (1991) Size effect on diagonal shear failure of beams without stirrups. ACI Structural Journal 89(3): 268-276.

Bažant ZP and Yu Q (2005a) Designing against size effect on shear strength of reinforced concrete beams without stirrups - I: Formulation. Journal of Structural Engineering ASCE 131(12): $1877-1885$.

Bažant ZP and Yu Q (2005b) Designing against size effect on shear strength of reinforced concrete beams without stirrups 
- II: Verification and calibration. Journal of Structural

Engineering ASCE 131(12): 1886-1897.

Bažant ZP and Yu Q (2009) Does strength test satisfying code requirement for nominal strength justify ignoring size effect in shear? ACI Structural Journal 106(1): 14-19.

CEN (European Committee for Standardisation) (2004) Eurocode 2: EN 1992-1-1: Design of concrete structures. Part 1-1: General rules and rules for buildings. CEN, Brussels, Belgium.

Chana PS (1987) Investigation of the mechanism of shear failure of reinforced concrete beams. Magazine of Concrete Research 39(141): 196-204.

Dei Poli S, Gambarova P and Karakoç C (1987) Aggregate interlock role in RC thin-webbed beams in shear. Journal of Structural Engineering ASCE 113(1): 1-19.

Dei Poli S, Di Prisco M and Gambarova P (1992) Shear response, deformations, and subgrade stiffness of a dowel bar embedded in concrete. ACI Structural Journal 89(6): 665675.

Dei Poli S, Di Prisco M and Gambarova P (1993) Cover and stirrup effects on the shear response of dowel bar embedded in concrete. ACI Structural Journal 90(4): 441-450.

Fenwick RC and Paulay T (1968) Mechanisms of shear resistance of concrete beams. Journal of the Structural Division ASCE 94(ST10): 2325-2350.

Fernández Ruiz M and Muttoni A (2009) Applications of the critical shear crack theory to punching of $\mathrm{R} / \mathrm{C}$ slabs with transverse reinforcement. ACI Structural Journal 106(4): 485-494.

Fernández Ruiz M, Muttoni A and Gambarova P (2007) Analytical modelling of the pre- and post-yield behaviour of bond in reinforced concrete. Journal of Structural Engineering ASCE 133(10): 1364-1372.

Fernández Ruiz M, Campana S and Muttoni A (2009) Discussion of paper: Influence of flexural reinforcement on shear strength of prestressed concrete beams by Saquan EI and Frosch RJ. ACI Structural Journal 106(6): 907-908.

Fernández Ruiz M, Muttoni A and Kunz J (2010) Strengthening of flat slabs against punching shear using post-installed shear reinforcement. ACI Structural Journal 107(4): 434-442.

fib (International Federation for Structural Concrete) (2011) fib Model Code 2010 Final Draft. fib. fib, Lausanne, Switzerland.

Guidotti R (2010) Poinçonnement des planchers-dalles avec colonnes superposées fortement sollicitées. $\mathrm{PhD}$ thesis, Ecole Polytechnique Fédérale de Lausanne, Lausanne, Switzerland, Thesis no. 4812 (in French).

Hillerborg A (1983) Analysis of a single crack. In Fracture Mechanics of Concrete (Wittmann FH (ed.)). Elsevier, Amsterdam, Netherlands, pp. 223-249.

Hordijk DA (1992) Tensile and tensile fatigue behaviour of concrete, experiments, modelling and analyses. Heron 37/1

Jelic I, Pavlovic MN and Kotsovos MD (1999) A study of dowel action in reinforced concrete beams. Magazine of Concrete Research 2(2): 131-141.

Kani GNJ (1964) The riddle of shear failure and its solution. ACI Journal 61(4): 441-467.
Kani GNJ (1966) Basic facts concerning shear failure. $A C I$ Journal 63(6): 675-692.

Kotsovos MD (1983) Mechanisms of shear failure. Magazine of Concrete Research 35(123): 99-106.

Kotsovos MD (1986) Behavior of beams with shear span-to-depth ratios greater than 2·5. ACI Structural Journal 83(6): 10261034.

Krefeld W and Thurston Charles W (1966a) Contribution of longitudinal steel to shear resistance of reinforced concrete beams. ACI Journal 63(3): 325-344.

Krefeld W and Thurston Charles W (1966b) Studies of the shear diagonal tension strength of simply supported reinforced concrete beams. ACI Journal 63(4): 451-476.

Kupfer H, Hilsdorf H and Rüsch H (1969) Behavior of concrete under biaxial stresses. Journal of the American Concrete Institute 66(8): 656-666.

Leonhardt F and Mönnig E (1974) Vorlesungen über Massivbau, Dritter Teil, Grundlagen zum Bewehren im Stahlbetonbau. Springer, Berlin, Germany (in German).

Muttoni A and Fernández Ruiz M (2007) Concrete cracking in tension members and application to deck slabs of bridges. Journal of Bridge Engineering ASCE 12(5): 646-653.

Muttoni A and Fernández Ruiz M (2008) Shear strength of members without transverse reinforcement as function of critical shear crack width. ACI Structural Journal 105(2): 163-172.

Paulay T and Loeber PJ (1974) Shear transfer by aggregate interlock. American Concrete Institute Special Publication SP-42: Shear in Reinforced Concrete, Vol. 1. American Concrete Institute, Detroit, MI, USA, pp. 1-16.

Paulay T, Park R and Phillips MH (1974) Horizontal construction joints in cast-in-place reinforced concrete. American Concrete Institute Special Publication SP-42: Shear in Reinforced Concrete, Vol. 2. American Concrete Institute, Detroit, MI, USA, pp. 599-616.

Sagaseta J and Vollum RL (2011) Influence of aggregate fracture on shear transfer through cracks in reinforced concrete. Magazine of Concrete Research 63(2): 119-137.

Sigrist V (1995) Zum Verformungsvermögen von Stahlbetonträgern. PhD thesis, ETHZ, Zurich, Switzerland, Thesis no. 11169 (in German).

Taylor HPJ (1969) Investigation of the Dowel Shear Forces Carried by the Tensile Steel in Reinforced Concrete Beams. Cement and Concrete Association, London, UK, Report no. TRA 431.

Taylor HPJ (1970) Investigation of the Forces Carried across Cracks in Reinforced Concrete Beams in Shear by Interlock of Aggregate. Cement and Concrete Association, London, UK, Technical Report no. 42.77.

Tureyen AK and Frosch RJ (2003) Concrete shear strength: another perspective. ACI Structural Journal 100(5): 609-615.

Ulaga T (2003) Betonbauteile mit stab-und lamellenbewehrung: verbund-und zuggliedmodellierung. $\mathrm{PhD}$ thesis, ETHZ, Zurich, Switzerland. Thesis no. 15062 (in German).

Walraven JC (1980) Aggregate Interlock: A Theoretical and Experimental Investigation. $\mathrm{PhD}$ thesis, Delft University of Technology, Delft, Netherlands. 
Zararis PD (1997) Aggregate interlock and steel shear forces in the analysis of RC membrane elements. ACI Structural Journal 94(2): 159-170.
Zararis PD (2003) Shear strength and minimum shear reinforcement of reinforced concrete slender beams. $A C I$ Structural Journal 100(2): 203-214.

\section{WHAT DO YOU THINK?}

To discuss this paper, please submit up to 500 words to the editor at www.editorialmanager.com/macr. Your contribution will be forwarded to the author(s) for a reply and, if considered appropriate by the editorial panel, will be published as a discussion in a future issue of the journal. 